\title{
Promise versus reality: a systematic review of the ongoing debates in people analytics
}

Ongoing debates in people analytics

Steven McCartney

\author{
School of Business, Maynooth University, Maynooth, Ireland, and \\ $\mathrm{Na} \mathrm{Fu}$ \\ Trinity Business School, Trinity College Dublin, The University of Dublin, Dublin, \\ Trinity Business School, Trinity College Dublin
Ireland
}

\begin{abstract}
Purpose - According to the significant growth of literature and continued adoption of people analytics in practice, it has been promised that people analytics will inform evidence-based decision-making and improve business outcomes. However, existing people analytics literature remains underdeveloped in understanding whether and how such promises have been realized. Accordingly, this study aims to investigate the current reality of people analytics and uncover the debates and challenges that are emerging as a result of its adoption. Design/methodology/approach - This study conducts a systematic literature review of peer-reviewed articles focused on people analytics published in the Association of Business School (ABS) ranked journals between 2011 and 2021.

Findings - The review illustrates and critically evaluates several emerging debates and issues faced by people analytics, including inconsistency among the concept and definition of people analytics, people analytics ownership, ethical and privacy concerns of using people analytics, missing evidence of people analytics impact and readiness to perform people analytics.

Practical implications - This review presents a comprehensive research agenda demonstrating the need for collaboration between scholars and practitioners to successfully align the promise and the current reality of people analytics.

Originality/value - This systematic review is distinct from existing reviews in three ways. First, this review synthesizes and critically evaluates the significant growth of peer-reviewed articles focused on people analytics published in ABS ranked journals between 2011 and 2021. Second, the study adopts a thematic analysis and coding process to identify the emerging themes in the existing people analytics literature, ensuring the comprehensiveness of the review. Third, this study focused and expanded upon the debates and issues evolving within the emerging field of people analytics and offers an updated agenda for the future of people analytics research.
\end{abstract}

Keywords People analytics, HR analytics, workforce analytics, Human resource management, Systematic literature review

Paper type Research paper

\section{Introduction}

People analytics has recently become an emerging trend within the field of human resource (HR) management (King, 2016; Marler and Boudreau, 2017; van den Heuvel and Bondarouk, 2017; Huselid, 2018; Kryscynski et al., 2018; McIver et al., 2018; Tursunbayeva et al., 2018; Ben-Gal, 2019). Likewise, it has been branded as a "game-changer" (van der Togt and Rasmussen, 2017) for $\mathrm{HR}$ departments as people analytics promises to enable evidence-based decision-making leading to improved business outcomes (Marler and Boudreau, 2017). As a result, people analytics has

C Steven McCartney and Na Fu. Published by Emerald Publishing Limited. This article is published under the Creative Commons Attribution (CC BY 4.0) licence. Anyone may reproduce, distribute, translate and create derivative works of this article (for both commercial and non-commercial purposes), subject to full attribution to the original publication and authors. The full terms of this licence may be seen at http://creativecommons.org/licences/by/4.0/legalcode

The authors would like to express their appreciation to Editor Professor Graeme Martin and the three anonymous reviewers for their valuable feedback and suggestions that significantly improved the paper.

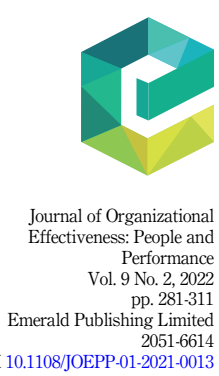

Received 19 January 2021

Revised 11 July 2021

22 November 2021

Accepted 9 December 2021

. 
JOEPP 9,2

282 become more attractive and has garnered significant interest among scholars and practitioners (Greasley and Thomas, 2020). For instance, in a review conducted by Marler and Boudreau (2017), 14 people analytics papers were published in journals featured on the Journal Quality List (JQL) between 2005 and 2016. Since then, the number of articles dedicated to people analytics has tripled, including two special issues dedicated to people analytics in the Association of Business Schools (ABS) ranked journals. One in the Journal of Organizational Effectiveness: People and Performance (2017: Volume 4, Issue 2, edited by Dana Minbaeva) and the second in Human Resource Management (2018: Volume 57, Issue 3, edited by Mark Huselid).

Meanwhile, in practice, the rapid digitalization of HR led by recent advancements in information technology (IT), such as human resource information systems (HRISs), artificial intelligence (AI) and machine learning (ML), has offered HR professionals the opportunity to collect, analyze and draw conclusions from people analytics (Baldry, 2011; Stone and Deadrick, 2015; Marler and Boudreau, 2017; van der Togt and Rasmussen, 2017; Buttner and Tullar, 2018; Huselid, 2018; McIver et al., 2018; Schiemann et al., 2018). For example, the people analytics team at Google has developed an analytical approach to their recruitment process, applying predictive analytics to calculate a candidate's likelihood of success using biographical data, personality data and employee attitudes (Harris et al., 2011).

Despite the promise that people analytics will inform evidence-based decision-making and improve business outcomes, the existing people analytics literature remains underdeveloped in understanding whether and how such promises have been realized. Accordingly, this study aims to investigate the current reality of people analytics by addressing the research question of what debates and challenges are emerging as a result of people analytics adoption? In response to this question, this study conducts a systematic literature review of peer-reviewed articles focused on people analytics published in the ABS ranked journals between 2011 and 2021. To do so, this study adopts a thematic analysis approach to systematically and critically evaluate the people analytics articles. Contrary to claims made by advocates of people analytics, this review uncovers several themes illustrating numerous challenges and emerging debates contrasting the promises offered by people analytics and the current reality of people analytics in organizations. Lastly, the review sets an agenda for future research by proposing six research areas critical to narrowing the gap created by these debates and shaping the future of research in people analytics.

This systematic review is distinct from existing reviews conducted by Marler and Boudreau (2017), Tursunbayeva et al. (2018) and Margherita (2020) in three ways. First, this review synthesizes and critically evaluates the significant growth of peer-reviewed articles focused on people analytics published in ABS ranked journals between 2011 and 2021. Second, the study adopts a thematic analysis and coding process to identify the emerging themes in the existing people analytics literature, ensuring the comprehensiveness of the review. Third, this study focuses and expands upon the debates and issues evolving within the emerging field of people analytics while offering a comprehensive agenda for the future of people analytics research.

The subsequent sections of this paper are organized as follows: First, the methodology section will outline the search process, including the rationale for the databases referenced, the keywords identified and the criteria used in selecting the appropriate articles. Additionally, the methodology section offers an evaluation of the selected articles, along with a description of the coding process. Second, the research findings section will present and critically evaluate the themes associated with the debates and challenges emerging as a result of people analytics adoption. Lastly, the discussion section will summarize the promise versus the current reality of people analytics while also setting out a comprehensive agenda for future research.

\section{Methodology}

\section{Literature search}

The literature search began with sourcing academic and peer-reviewed journal articles from five databases: ABI/Inform, Business Source Complete, Emerald, SCOPUS and the Wiley 
Online Library. Each database was selected due to its comprehensive range of peer-reviewed articles and access to leading management journals. Additionally, both Business Source Complete and SCOPUS were included to maintain consistency with the databases used by Marler and Boudreau (2017) in their evidence-based review.

The following key search terms were used to identify and select articles for inclusion: "Workforce Analytics"; "HR Analytics"; "Human Resource Analytics"; "People Analytics"; "Human Capital Analytics"; "Talent Analytics". Each of the search terms was selected as they have been used synonymously in practice and in the academic literature to refer to people analytics (van den Heuvel and Bondarouk, 2017; Huselid, 2018; McIver et al., 2018; Tursunbayeva et al., 2018; Ben-Gal, 2019). The result of the initial literature search yielded 2,725 articles and studies between the five databases. Table 1 summarizes the distribution of results from different databases.

\section{Selection process and screening criteria}

After conducting the initial literature search, the 2,725 articles and studies were transferred into an excel spreadsheet and organized using 11 categories: database, author(s), article title, year published, journal title, volume number, issue number, peer-review, journal field, ABS ranking and abstract. As a result, 1,895 of the 2,725 results were excluded due to not being peer-reviewed articles, resulting in 830 journal articles remaining. Next, the remaining journal articles were screened using three selection and inclusion criteria: (1) journals must appear on the ABS journal rankings, (2) articles must be published in an English language journal and (3) articles are published between the years between 2011 and 2021. The years 2011 and 2021 were chosen due to the first people analytics paper being published in an ABS ranked journal in 2011 (Marler and Boudreau, 2017). Articles were also screened based on their perceived relevance to people analytics through their title and abstract. After removing all duplicate journal articles (784), 46 articles were identified as relevant for the review. Figure 1 outlines the systematic approach taken concerning the literature search.

\section{Evaluation of selected articles}

The 46 articles identified through the literature search represent the considerable growth in academic publications and demonstrates how the field of people analytics has progressed since 2011. In particular, many of these studies have been published in the last few years, illustrating the demand for people analytics research. For example, of the 46 articles identified as relevant for this review, 37 were published between 2017 and 2021. Figure 2 below highlights the increase of people analytics publications in ABS ranked journals from 2011 to 2021.

In terms of journal distribution, the articles identified through the literature search represent 28 distinct academic journals, demonstrating the wide array of journals accepting people analytics research. Table 2 shows the ABS ranked journal distribution of published people analytics articles.

\begin{tabular}{lc}
\hline Journal & Results from literature search \\
\hline ABI/Inform & 994 \\
Business Source Complete & 304 \\
Emerald & 268 \\
SCOPUS & 117 \\
Wiley Online Library & 1,042 \\
In total & 2,725 \\
Full-text articles assessed for eligibility & $830^{*}$
\end{tabular}

Note(s): ${ }^{*}$ The number was reduced from 2,725 to 830 due to 1,895 of the 2,725 results not being peer-reviewed

\section{Ongoing debates in people analytics}

283

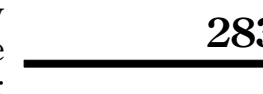




\section{JOEPP \\ 9,2}

\section{4}

Figure 1.

Systematic literature search
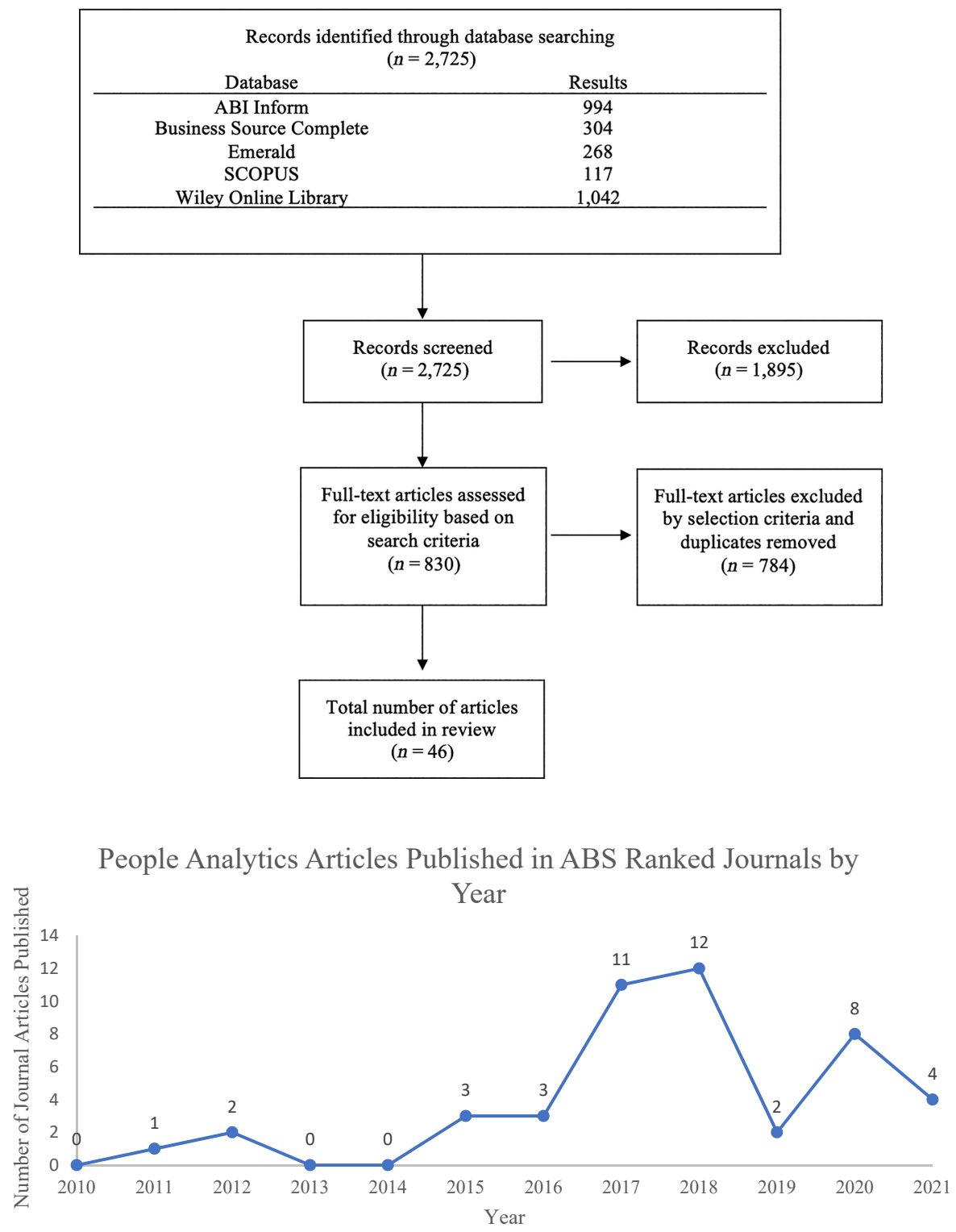

Literature review and coding method

A thematic analysis was conducted using the 46 articles to ascertain the underlying themes, trends and recent developments in the people analytics literature. Thematic analysis was the chosen method as it allows for the clear identification and classification of themes and patterns using a systematic coding process (Boyatzis, 1998; Braun and Clarke, 2006; Ibrahim, 2012). Similarly, performing a thematic analysis can provide a high degree of detail and help interpret many aspects of the research question or research topic (Braun and Clarke, 2006). 


\begin{tabular}{|c|c|c|c|c|c|}
\hline Journal title & $\begin{array}{l}\text { Journal } \\
\text { ranking } \\
\text { (ABS) }\end{array}$ & $\begin{array}{c}\text { Number of } \\
\text { articles } \\
\text { published } \\
\end{array}$ & ABS field & $\begin{array}{c}\text { Total articles } \\
\text { published by ABS } \\
\text { field } \\
\end{array}$ & $\begin{array}{r}\text { Ongoing } \\
\text { debates in } \\
\text { people }\end{array}$ \\
\hline Harvard Business Review & 3 & 1 & ETHICS-CSR-MAN & $18 \%$ & analytics \\
\hline Journal of Business Research & 3 & 1 & ETHICS-CSR-MAN & & \\
\hline MIT Sloan Management Review & 3 & 2 & ETHICS-CSR-MAN & & \\
\hline Business Horizons & 2 & 1 & ETHICS-CSR-MAN & & 285 \\
\hline $\begin{array}{l}\text { Journal of General Management } \\
\text { Equality, Diversity, and Inclusion: }\end{array}$ & $\begin{array}{l}2 \\
1\end{array}$ & $\begin{array}{l}1 \\
1\end{array}$ & $\begin{array}{l}\text { ETHICS-CSR-MAN } \\
\text { ETHICS-CSR-MAN }\end{array}$ & & 205 \\
\hline An International Journal & & & & & \\
\hline Management Research Review & 1 & 1 & ETHICS-CSR-MAN & & \\
\hline Human Resource Management & 4 & 6 & HRM\&EMP & $58 \%$ & \\
\hline $\begin{array}{l}\text { Human Resource Management } \\
\text { Journal }\end{array}$ & 4 & 2 & HRM\&EMP & & \\
\hline $\begin{array}{l}\text { Human Resource Management } \\
\text { Review }\end{array}$ & 3 & 1 & HRM\&EMP & & \\
\hline $\begin{array}{l}\text { International Journal of Human } \\
\text { Resource Management }\end{array}$ & 3 & 3 & HRM\&EMP & & \\
\hline Employee Relations & 2 & 1 & HRM\&EMP & & \\
\hline $\begin{array}{l}\text { Human Resource Development } \\
\text { Review }\end{array}$ & 2 & 1 & HRM\&EMP & & \\
\hline $\begin{array}{l}\text { International Journal of } \\
\text { Manpower }\end{array}$ & 2 & 1 & HRM\&EMP & & \\
\hline $\begin{array}{l}\text { Journal of Organizational } \\
\text { Effectiveness: People and } \\
\text { Performance }\end{array}$ & 2 & 8 & HRM\&EMP & & \\
\hline Persomnel Review & 2 & 2 & HRM\&EMP & & \\
\hline $\begin{array}{l}\text { Journal of Work-Applied } \\
\text { Management }\end{array}$ & 1 & 1 & HRM\&EMP & & \\
\hline Competitiveness Review & 1 & 1 & IB\&AREA & $2 \%$ & \\
\hline Decision Support Systems & 3 & 1 & INFO MAN & $7 \%$ & \\
\hline $\begin{array}{l}\text { Expert Systems: The Journal of } \\
\text { Knowledge Engineering }\end{array}$ & 2 & 1 & INFO MAN & & \\
\hline $\begin{array}{l}\text { International Journal of } \\
\text { Information Management }\end{array}$ & 2 & 1 & INFO MAN & & \\
\hline Organizational Dynamics & 2 & 1 & ORG STUD & $4 \%$ & \\
\hline $\begin{array}{l}\text { International Journal of } \\
\text { Organizational Analysis }\end{array}$ & 1 & 1 & ORG STUD & & \\
\hline Management Science & $4 *$ & 1 & ORG\&MANSCI & $9 \%$ & \\
\hline $\begin{array}{l}\text { European Journal of Operational } \\
\text { Research }\end{array}$ & 4 & 1 & ORG\&MANSCI & & \\
\hline Journal of Forecasting & 2 & 1 & ORG\&MANSCI & & \\
\hline Kybernetes & 1 & 1 & ORG\&MANSCI & & Journal distribution in \\
\hline Journal of Business Strategy & 1 & 1 & STRAT & $2 \%$ & \\
\hline \multicolumn{6}{|c|}{ Note(s): ABS journals are ranked from $4^{*}$ (highest) to 1 (lowest) } \\
\hline
\end{tabular}

To conduct the thematic analysis, NVivo, a text analysis software program, was used. The 46 articles were loaded into a new NVivo project for analysis. Following best practices in conducting thematic analysis (Boyatzis, 1998; Braun and Clarke, 2006; Fereday and MuirCochrane, 2017; Williams and Moser, 2019), an inductive coding approach was used to develop themes concerning the debates and challenges currently evolving within the people analytics literature. An inductive coding approach was favored as it allowed the research team to gain insight from the data without any preconceived themes or theory to influence theme development (Glaser and Strauss, 1967; Williams and Moser, 2019). To uncover the underlying debates and challenges, each of the 46 papers was read to familiarize and understand the selected articles. Next, open coding was performed to generate initial codes and concepts from the data. Open codes included keywords, phrases and statements found 

JOEPP
9,2

286

within each of the 46 articles that offered either a positive or negative opinion toward the current state of people analytics adoption. Keywords, phrases and statements that did not express a clear opinion were excluded. Once all codes had been identified, axial coding was then employed to refine the initial open codes and divide them into clearly defined groups and subgroups (Liamputtg, 2009; Simmons, 2018; Williams and Moser, 2019). The axial coding process involved the research team determining relationships between each of the open codes and grouping codes into concepts related to their position toward a challenge or debate as a result of people analytics adoption. Finally, derived from the axial coding process, selective coding was employed to classify the main thematic categories concerning the debates and challenges facing people analytics (Williams and Moser, 2019). To do so, the research team refined each concept emerging from the axial coding process concentrating on further developing, defining and articulating each challenge and debate within the context of people analytics adoption.

\section{Research findings}

As evidenced by the growth of people analytics research, the field has made significant steps forward over the past several years. For example, the majority of recent research has offered much-needed insight into several key areas, including the current limitations and challenges facing the development of people analytics (Andersen, 2017; Boudreau and Cascio, 2017; Levenson and Fink, 2017; van der Togt and Rasmussen, 2017; Huselid, 2018; Minbaeva, 2018; Jeske and Calvard, 2020), best practices in utilizing people analytics (Green, 2017; Peeters et al., 2020), the impact and importance of analytical skills (Andersen, 2017; Kryscynski et al., 2018; McIver et al., 2018; Minbaeva, 2018; Vargas et al., 2018; McCartney et al., 2020) and the potential future applications of people analytics by drawing upon practitioner experience and case studies (van den Heuvel and Bondarouk, 2017; van der Togt and Rasmussen, 2017; Minbaeva, 2018; Schiemann et al., 2018; Simón and Ferreiro, 2018). A summary of the 46 articles included in the review can be found in Appendix. However, this growth of people analytics literature coupled with organizations implementing and adopting people analytics to make strategic workforce decisions have given rise to several debates and challenges currently faced by HR and business professionals.

These emerging debates and issues center around five major themes: (1) the inconsistency among the concept and definition of people analytics, (2) missing empirical evidence for the performance impact of people analytics, (3) not ready to perform people analytics (4) people analytics ownership and (5) ethical and privacy concerns of using people analytics. Table 3 presents quotes taken from journal articles that illustrate each theme and the percentage of articles that address the theme. The debate and issue are then discussed and critically evaluated.

\section{Inconsistency among the concept and definitions of people analytics}

Despite its popularity, a clear definition of people analytics has yet to be established among scholars and professionals due in part to the various terms used synonymously to describe the concept of people analytics (Levenson and Fink, 2017; Marler and Boudreau, 2017; van den Heuvel and Bondarouk, 2017; Huselid, 2018; McIver et al., 2018; Tursunbayeva et al., 2018; Ben-Gal, 2019). One example is the term HR metrics, which has been used interchangeably and synonymously with people analytics, despite being a very different and distinct concept.

For instance, according to van den Heuvel and Bondarouk (2017), "Given that HR analytics explicitly involves linking people characteristics, HR practices or policies, and business outcomes, the analytics concept is distinct and the term should not be used interchangeably with the term metrics" (p. 131).

Moreover, van den Heuvel and Bondarouk (2017) suggest that a key differentiator between the two concepts is that "metrics do not provide a robust insight into why something 


Illustrative quotes
"In addition to Workforce Analytics, the terms HR
Metrics, HR Analytics, Talent Analytics, Human
Capital Analytics, and People Analytics have all been
used to describe this field" (Huselid, 2018, p. 680)
"Despite the promise, successful strategic HR
analytics projects appear to be few and far between.
Although many organizations have begun to engage
with HR data and analytics, most have not
progressed beyond operational reporting" (Angrave
et al., 2016, p. 4)
"Success with human capital analytics will depend, in
large part, on HR's ability to find and nurture
analytical talent - the people who produce the data,
the quantitative analysis, and statistical models you
need to make better decisions and achieve better
results. Connecting these specialists with the
business will ensure that they understand how
human capital analytics can drive value for the
business" (Harris et al., 2011, p. 11)
"Take HR analytics out of HR. This may sound
drastic, but when HR analytics matures, it initially
starts cooperating more with other departments'
teams (in finance, operations, etc.), and eventually
becomes part of cross functional/end-to-end analytics
- looking at human capital elements in the entire
value-chain" (Rasmussen and Ulrich, 2015, p. 238 )
"Company-collected relational data, however, create
new challenges. Although most employment
contracts give firms the right to record and monitor
activities conducted on company systems, some
employees feel that the passive collection of relational
data is an invasion of privacy" (Leonardi and
Contractor, 2019, p. 15)
and

Percentage of articles addressing theme

Theme

60

Inconsistency among the concept and definition of people analytics

Missing evidence of people analytics impact

54

Not ready to perform people analytics

People analytics ownership debate

24

Ethical and privacy concerns of using people analytics
287

Ongoing debates in people analytics

Table 3.

Quotes and themes for the debates and issues of people analytics adoption

occurred, what explains differences in outcomes, or what the likelihood is that an event will reoccur in the future" (p. 131).

Accordingly, scholars have begun to propose several definitions and descriptions to illustrate and add clarity around the concept of people analytics. However, rather than adding clarity, this practice has highlighted several inconsistencies surrounding the concept of people analytics.

For example, Marler and Boudreau (2017) suggest that people analytics can be defined as "[a]n HR practice enabled by information technology that uses descriptive, visual, and statistical analyses of data related to HR processes, human capital, organizational performance, and external economic benchmarks to establish business impact and enable data-driven decisionmaking" (p. 15).

In contrast, Huselid (2018) defines people analytics as "The process involved in understanding, qualifying, managing, and improving the role of talent in the execution of strategy and creation of value. It included not only a focus on metrics (e.g. what do we need to measure about our workforce?) but also analytics (e.g. how do we manage and improve the metrics we deem to be critical for business success)" (p. 680).

Table 4 below summarizes the varying definitions and the terms associated with people analytics. 


\section{JOEPP \\ 9,2}

288

Table 4.

Definitions of people analytics
高

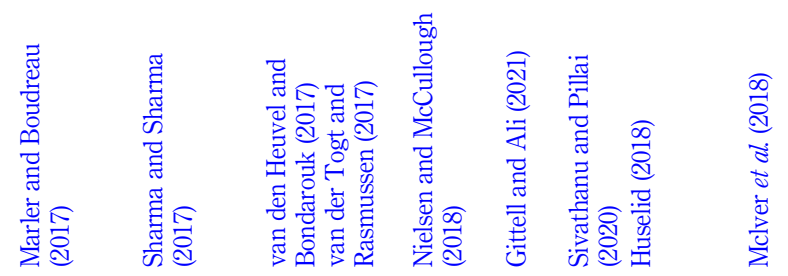

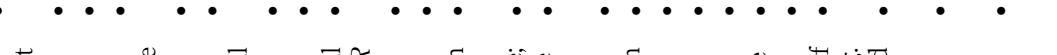

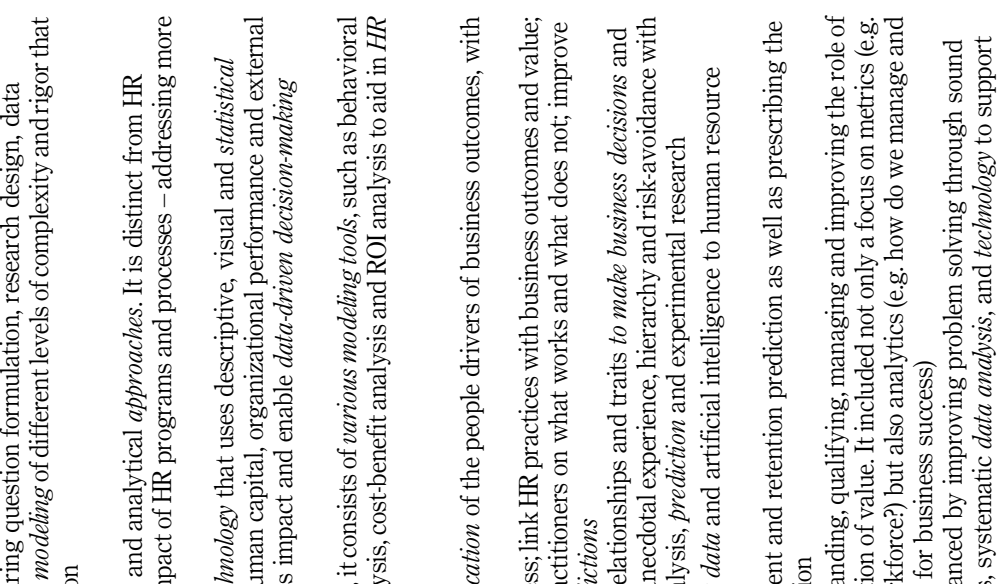

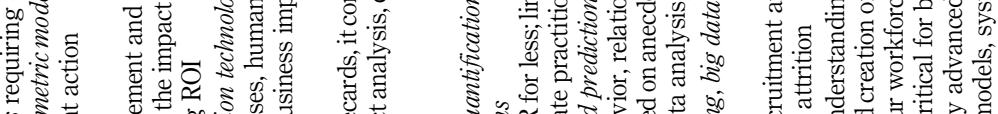

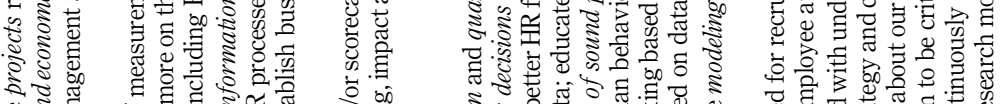

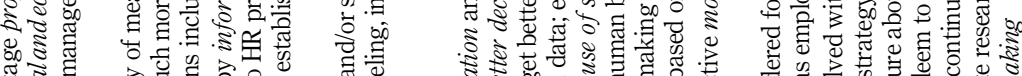

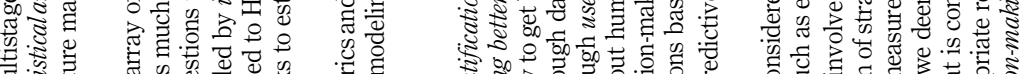

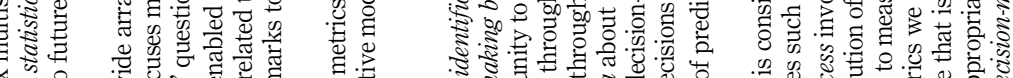

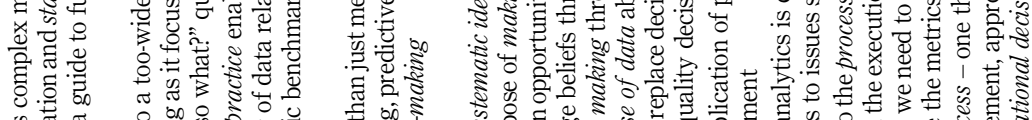

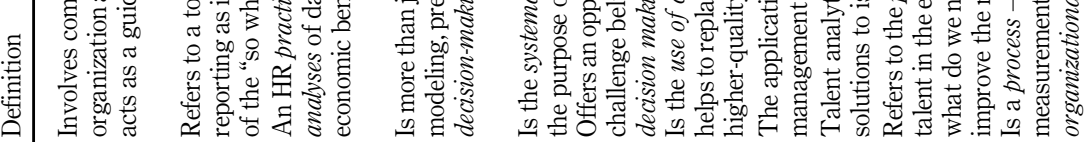

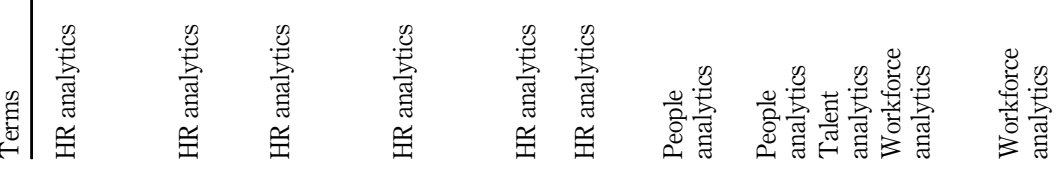


In addition to these conceptualizations, various scholars such as Margherita (2020) and Sivathanu and Pillai (2020) have claimed that people analytics is not one dimensional but instead falls along a spectrum where the maturity of the people analytics function will determine the level of analytics that can be conducted.

For example, according to Margherita (2020), "Three main stages of evolution can be identified which are characterized by different levels of difficulty, value, and intelligence. First, "descriptive" analytics, aiming to answer questions related to what happened, why it happened, and what is happening. Second, "predictive analytics", answering questions such as what will happen and why will it happen in the future. Third, "prescriptive" analytics, aimed to answer questions such as what should I do and why should I do it."

Overall, it is evident that there are several inconsistencies between how scholars and practitioners view, label and define people analytics. Together, however, they agree that people analytics involves using workforce data to help make better decisions, which can occur at various levels of maturity. As such, people analytics should be seen as situational, falling along a spectrum where organizations at the low end of maturity report on descriptive statistics. In contrast, organizations at the highest and most mature level of people analytics can utilize descriptive statistics and more advanced forms of technology (i.e. AI, ML and organizational network analysis tools) to analyze workforce data to perform predictive and prescriptive analytics. Therefore, drawing upon several definitions from the extant literature and the people analytics maturity model (Margherita, 2020; Sivathanu and Pillai, 2020; Chatterjee et al., 2021), we suggest people analytics can be conceptualized as the continuous process of transforming and translating workforce data into organizational insights at varying levels of sophistication, enabling managers to make data-driven workforce decisions. We propose this new conceptual definition for two reasons. First, it offers a holistic perspective of the concept considering the people analytics process from the start (incorporating the transformation and translation of data) to finish (generating organizational insights). Second, the definition considers the concept's progressive aspect, referring to the maturity spectrum of people analytics, which is absent in current definitions.

\section{Missing empirical evidence for the performance impact of people analytics}

Given the rise of people analytics adoption in industry, professional associations, including the Chartered Institute of Personnel and Development (CIPD) and consulting firms, such as Deloitte, have begun to claim the benefits of people analytics by publishing blogs, white papers and reports (Marler and Boudreau, 2017). This practitioner-focused perspective has led to several case studies being published demonstrating how HR departments can leverage people analytics to address HR and business challenges (Harris et al., 2011; Kane, 2015; Buttner and Tullar, 2018; McIver et al., 2018). However, despite the belief in people analytics among practitioners, scholars remain skeptical, questioning the legitimacy of people analytics and whether HR departments should adopt people analytics altogether (Rasmussen and Ulrich, 2015; Angrave et al., 2016; Andersen, 2017; Baesens et al., 2017; Levenson and Fink, 2017; Marler and Boudreau, 2017; McIver et al., 2018). This is due to the lack of empirical evidence supporting the claims that people analytics can aid in strategic decision-making (Rasmussen and Ulrich, 2015; Baesens et al., 2017; Levenson and Fink, 2017; Marler and Boudreau, 2017; Huselid, 2018; Greasley and Thomas, 2020; Larsson and Edwards, 2021).

For example, Marler and Boudreau (2017) claim that "despite evidence of a growing interest in this innovation, we found very little and limited scientific evidence to aid decision-making concerning whether to adopt HR analytics” (p. 20).

Likewise, Rasmussen and Ulrich (2015) state that "So far the published evidence supporting the alleged value of HR analytics is actually quite slim - it is currently based more on belief than evidence, and most often published by consultants with a commercial interest in the HR analytics market, while organizations rarely share the same success stories of business impact” (p. 236).

\section{Ongoing debates in people analytics}

289 
JOEPP
9,2
Additionally, it has become clear that very few organizations can evaluate and determine the business value that people analytics provides to their organizations (Rasmussen and Ulrich, 2015; Angrave et al., 2016; King, 2016; Andersen, 2017; Baesens et al., 2017; Marler and Boudreau, 2017; Huselid, 2018; McIver et al., 2018; Schiemann et al., 2018).

For example, Andersen (2017) claims that "A few very large multinational companies have set up large HR analytics division and have embarked well on the journey. Many of their cases and results point to interesting and not least value-added findings" (p. 134).

Moreover, McIver et al. (2018) state that "despite substantial publicity, a challenge remains for understanding how organizations can successfully use workforce analytics to influence organizational outcomes" (p. 2).

This is echoed by Huselid (2018), who claims that "Despite the recent popularity of workforce analytics, there is much that we do not yet know about the processes through which analytics affects the strategy execution process in organizations and, ultimately, firm success" (p. 680).

This debate is predicated on the longstanding tension between practice and academia. On the one hand, people analytics practitioners argue that the evidence offered by these case studies demonstrates the impact people analytics can have in solving HR challenges. In contrast, those in academia take a different stance, looking for more empirical evidence and generalizable findings. Our aim is not to discredit the results of these case studies as they offer much-needed insight into how people analytics is being implemented within industry. However, we argue that until future academic research can empirically link people analytics to unit-level and organizational level outcomes, people analytics is nothing more than an organizational myth.

\section{Not ready to perform people analytics}

Despite the fact HR departments have invested in human capital software and developed people analytics teams, many scholars question whether these functions are ready to perform people analytics (Angrave et al., 2016; Edwards and Edwards, 2019). These concerns can be divided into three groups: first, the lack of analytical skills among HR professionals, second, questionable data quality and third, outdated or unsophisticated HR technology.

Lack of analytical skills among HR professionals. For people analytics to be successful and effectively enable organizations to make more informed and strategic data-driven decisions, HR professionals must possess a variety and diverse set of skills (Harris et al., 2011; Rasmussen and Ulrich, 2015; Angrave et al., 2016; Marler and Boudreau, 2017; Kryscynski et al., 2018; McCartney et al., 2020).

For example, Marler and Boudreau (2017) state that "in order to implement HR analytics effectively, companies need employees with the right knowledge and skills to collect the correct data, perform the right statistical analyses and then to communicate the results in a meaningful and accessible way" (p. 22).

Furthermore, Harris et al. (2011) argue that "success with human capital analytics will depend, in large part, on HR's ability to find and nurture analytical talent - the people who produce the data, the quantitative analysis, and statistical models you need to make better decisions and achieve better results" (p. 11).

Accordingly, academic literature has begun to propose and debate a wide range of skills and competencies required by HR professionals to effectively conduct people analytics (Andersen, 2017; van der Togt and Rasmussen, 2017; Kryscynski et al., 2018; McIver et al., 2018; Minbaeva, 2018; Vargas et al., 2018).

For example, according to Kryscynski et al. (2018), for HR to properly engage in analytics, "HR professionals must have the abilities to perform the needed analyses. For the HR function to ensure appropriate measures, HR professionals must be able to individually identify appropriate data and information [...] HR professionals must have the ability to translate results into understandable and actionable insights for managers" (p. 717). 
Similarly, McIver et al. (2018) suggest that "Workforce analytics professionals must be able to ask the right questions, determine the right metrics, and provide evidence that enables strategic decision makers to understand trade-offs among alternative courses of HR actions (policies, practices, investments)" (p. 10).

Recently, taking these perspectives into account, McCartney et al. (2020) have developed a competency model for HR analysts where they "offer evidence supporting a set of six distinct competencies required by HR Analysts including: consulting, technical knowledge, data fluency and data analysis, HR and business acumen, research and discovery and storytelling and communication" (p. 1).

Questionable data quality. High-quality data are essential for conducting value-added people analytics (Fernandez and Gallardo-Gallardo, 2020; Jeske and Calvard, 2020). However, many organizations still struggle to have confidence in their HR and people data (King, 2016; Pape, 2016; Andersen, 2017; Boudreau and Cascio, 2017; McIver et al., 2018; Minbaeva, 2018; Jeske and Calvard, 2020). For example, in a Deloitte study (Deloitte, 2017) of over 10,000 business and HR leaders (as cited in McIver et al., 2018), only 8\% of HR leaders surveyed reported being confident using the data they have access to. Therefore, attaining and maintaining high-quality data has become a significant limitation faced by HR departments. This difficulty arises as workforce data tend to be vast, messy, constantly changing and held in several different data sources (Harris et al., 2011; Andersen, 2017; Boudreau and Cascio, 2017; Levenson and Fink, 2017; McIver et al., 2018; Minbaeva, 2018).

For example, according to Minbaeva (2018), "most firms do not know what types of data are already available to them or in what form. In fact, most firms do not have the answers to some basic questions: What data do we have? Where do we store it? How was the data collected? [...] Such poor organization of firm data can be very costly” (p. 702).

Likewise, Fernandez and Gallardo-Gallardo (2020) claim that "there may be insufficient data to be able to "ask the right questions" (i.e. to use HR analytics in an optimal way). Indeed, the lack of existing data items has been identified as one of the major barriers for succeeding in implementing analytics" (p. 11).

Outdated or unsophisticated HR technology. Continuous investment in HR technology over the past 15 years has played a significant role in developing and executing people analytics (Boudreau and Cascio, 2017; Marler and Boudreau, 2017). The HRIS serves as a foundation for people analytics by enabling HR departments to collect, extract and analyze large amounts of data (King, 2016; Marler and Boudreau, 2017; Sharma and Sharma, 2017; McIver et al., 2018). Moreover, the HRIS offers HR professionals better insight into the workforce as they provide the capability to produce interactive dashboards and scorecards, which highlight key workforce measures in several areas, such as compensation, employee engagement, employee performance, diversity and inclusion and talent management (Aral et al., 2012; Kapoor and Sherif, 2012; Marler and Boudreau, 2017; van der Togt and Rasmussen, 2017). However, scholars have noted that the functionality of HR technology fails to deliver the appropriate solutions necessary for performing advanced and predictive analytics (Angrave et al., 2016; King, 2016; Andersen, 2017; Boudreau and Cascio, 2017; Marler and Boudreau, 2017; Fernandez and Gallardo-Gallardo, 2020).

For example, Angrave et al. (2016) suggest that "Rather than providing strategic and predictive analytics that allow organizations to ask and answer big questions about how value can be created, captured and leveraged, HRIS typically provide answers to a more limited set of questions focused on operational reporting [. . .] the costly analytics capabilities provided by the latest forms of HRIS are failing to deliver strategic HR analytics capabilities” (p. 5).

Similarly, King (2016) suggests that "the ability for analytics to be applied in a meaningful way has been hindered, not helped, by the growing HR analytics industry, which is often built upon products and services that fail to meet the needs of HR professionals and organizations" (p. 491). 

JOEPP
9,2
Likewise, Fernandez and Gallardo-Gallardo (2020) state that "developers of software for predictive and prescriptive HR analytics do not understand the context specific causality of each organization and that managers do not have the knowledge and skills to adapt their environment to the standard model proposed in the software" (p. 14). Thus, becoming more of an impediment and barrier to people analytics.

Even though progress has been made over the last few years, the absence of analytical capabilities, high-quality data and adequate technology underlie the challenges faced by people analytics. For instance, it has been claimed that many of the competencies and skills required by $\mathrm{HR}$ professionals to conduct people analytics are not currently found within $\mathrm{HR}$ departments but rather reside elsewhere within the organization (Ulrich and Dulebohn, 2015; Green, 2017; van den Heuvel and Bondarouk, 2017). Professional associations, such as CIPD, have developed training programs aimed at upskilling $\mathrm{HR}$ professionals in these areas to address this gap. Likewise, more and more universities globally are now offering programs or modules dedicated to people analytics aimed at developing analytical capabilities and preparing students to work in people analytics roles. As such, we suspect that the skills gap is smaller than current research might suggest; however, there is still a long way to go.

Additionally, the lack of organization and centralized storage location for data has also lead to several issues, including data duplication, incorrect and inaccurate entries and missing data (King, 2016; Boudreau and Cascio, 2017; Levenson and Fink, 2017; Minbaeva, 2018; Shet et al., 2021). According to Andersen (2017), this lack of data quality in HR can be attributed to the lack of a coherent data strategy, not understanding the strategic importance of data, poor data management and a lack of critical data sources. Concerning this issue, we agree that this is still a work in progress for most people analytics teams and is hindering people analytics progress. Finally, with respect to technology, companies such as Workday, Oracle and SAP have made significant strides in addressing the lack of advanced analytical functionality needed for people analytics (Gartner, 2021). Further, for people analytics teams operating at the higher ends of people analytics maturity, additional forms of IT, such as business intelligence (BI) and data analytics platforms, have been integrated with their current HRIS to generate HR intelligence (Kapoor and Sherif, 2012; Sivathanu and Pillai, 2020). For example, HRIS providers are offering advanced modules featuring BI and data analytics capabilities to enable HR professionals to form predictions and to make more informed data-driven decisions through the use of online analytical processing (OLAP), data mining techniques, perform advanced statistical analysis and the development of analytical models for forecasting and engaging in predictive analytics (Kapoor and Sherif, 2012). Similarly, those at the highest level of people analytics maturity are also modeling their workforce data using AI algorithms in open-source statistical platforms, such as $R$ and Python, to make predictions about their workforce (Gelbard et al., 2018; Margherita, 2020; Shet et al., 2021; Tursunbayeva et al., 2021). Overall, given the advancements in people analytics technology, we suggest that current HRIS capabilities coupled with the flexibility offered by open-source statistical platforms have improved the deficit faced by HR technology platforms of the past.

\section{People analytics ownership debate}

Recently, scholars have begun to debate whether people analytics should remain within the domain of HR or be relocated into a centralized analytics team (Rasmussen and Ulrich, 2015; Andersen, 2017; Marler and Boudreau, 2017; van den Heuvel and Bondarouk, 2017; Minbaeva, 2018; Fernandez and Gallardo-Gallardo, 2020). A study conducted by van den Heuvel and Bondarouk (2017) found that $50 \%$ of respondents expect people analytics to become part of a centralized analytics team working independently of HR. Conversely, $35 \%$ of respondents suggested that people analytics would remain in $\mathrm{HR}$, playing an essential role as a center of excellence, offering data analysis in areas such as training, performance 
management and compensation and benefits. Those who argue for removing people analytics suggest that if kept solely within the HR function, it will miss out on opportunities to collaborate with other departments and stakeholders, gain access to data-rich sources and limit its strategic potential (Rasmussen and Ulrich, 2015; Andersen, 2017; Fernandez and Gallardo-Gallardo, 2020).

For example, Rasmussen and Ulrich (2015) have called for removing people analytics from HR, stating, "Take HR analytics out of HR. This may sound drastic, but when HR analytics matures, it initially starts cooperating more with other departments' teams (in finance, operations, etc.), and eventually becomes part of cross-functionallend-to-end analytics looking at human capital elements in the entire value-chain" (p. 238).

Moreover, Marler and Boudreau (2017) argue that "An appropriate collaboration between HR leaders and functional experts in disciplines such as finance, operations, marketing, and engineering may be key to developing the logical frameworks for HR analytics that can engage key decision-makers and connect more clearly to organizational outcomes" (p. 19).

Similarly, Andersen (2017), states that those who suggest removing people analytics from $\mathrm{HR}$ argue that "HR analytics will lose its strategic potential as HR in many organizations are more operational and tactical than strategically focused" (p. 135). Moreover, he suggests that "HR does not have ownership of all relevant data as many reside in finance (payroll), IT, legal, and sales" (Andersen, 2017, p. 135), which is a critical issue when relying on various data sources to make evidence-based strategic workforce decisions.

In contrast, those who argue in favor of keeping people analytics within the HR department suggest that other functions, such as finance, marketing or IT, will not be as committed to acting on the insights generated by workforce data and that people models will be built without HR interests in mind (Angrave et al., 2016; Andersen, 2017; Marler and Boudreau, 2017).

For example, Andersen (2017) suggests that "nobody else cares about HR data and insights (as much as HR do), it takes HR knowledge to interpret and convert HR data to knowledge and information, it may make HR more data-driven and improve HR impact on business, data ownership sits naturally in HR and finally it will increase the likelihood of the analytics actually being used" (p. 135).

Moreover, Angrave et al. (2016) state that "If HR is not fully involved in the modeling process, there is significantly greater scope for models to be constructed in a way which fundamentally misunderstands the nature of human capital inputs" (p. 7).

Overall, each side of this debate has merit. On the one hand, keeping people analytics within the HR function allows insights gathered from people analytics to be interpreted within the context of HR, thus offering and developing solutions that can aid in addressing specific HR challenges. Likewise, keeping people analytics within $H R$ will alleviate any issues regarding data privacy as moving people analytics outside $\mathrm{HR}$ will pose a risk around what sensitive data are available and being used by those in non-HR roles. Furthermore, removing people analytics from the HR function may suggest to the HR department that they are not seen as strategic partners.

On the other hand, the alternative perspective of moving people analytics outside of $\mathrm{HR}$ focuses on the lack of analytical skills, data quality and outdated technology currently found within the HR department. For example, there appears to be a significant shortage among HR professionals who possess the required skills and competencies to perform people analytics. Additionally, those who suggest the removal from HR claim that keeping people analytics within HR hinders their ability to collaborate and access data from other departments, such as finance, IT or marketing. Despite the claims made by each side, there is no clear winner in this debate. However, a balance can be struck between both sides where people analytics remains centralized within HR while addressing the main limitations suggested for removing people analytics from the HR function. To do so, we propose that people analytics needs to

\section{Ongoing debates in people analytics}

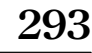


JOEPP 9,2 take a highly collaborative approach through building boundary-spanning relationships aimed at facilitating cross-functional collaboration with departments, such as IT, finance and marketing. By doing so, people analytics can obtain access to external data sources and expertise from other business units, overcoming the restrictions of insufficient skills and limited access to data. Moreover, we suggest that people analytics should emphasize and encourage acquiring members from other disciplines, including IT and data science, on a project-by-project basis or assimilate them into the team full-time. Altogether, we believe that keeping people analytics within HR is critical to the long-term survivability of the function and may result in positive spillover effects including, the visibility and credibility of HR.

\section{Ethical and privacy concerns of using people analytics}

There has been a significant increase in organizations using IT, such as cell phones, email, social media, microphones, motion sensors and wearable technology, to collect and analyze real-time employee data (Kane, 2015; Hurrell et al., 2017; Khan and Tang, 2017; Strohmeier, 2018; Leonardi and Contractor, 2019; Jeske and Calvard, 2020; Kellogg et al., 2020). Furthermore, AI, data mining, ML and the Internet of things (IoT) enable organizations to capture data related to employees' personal views, sentiments and behaviors (Gelbard et al., 2018; Jeske and Calvard, 2020; Kellogg et al., 2020). For instance, in addition to collecting biographical data, such as age, gender and tenure, organizations have also begun to collect and analyze large amounts of relational data. These data include movement patterns through Bluetooth technology, voice recordings that monitor whom employees are interacting with and with whom they are speaking to most frequently and employee moods through facial recognition software (Kane, 2015; Gelbard et al., 2018; Leonardi and Contractor, 2019; Tursunbayeva et al., 2021).

These new forms of collecting employee data presents HR professionals and organizations with an emerging challenge concerning how to ensure the privacy and security of employee data while also navigating how data are being used and analyzed ethically (Leonardi and Contractor, 2019; Falletta and Combs, 2020; Jeske and Calvard, 2020; Chatterjee et al., 2021; Shet et al., 2021).

According to Leonardi and Contractor (2019), "Company-collected relational data, however, creates new challenges. Although most employment contracts give firms the right to record and monitor activities conducted on company systems, some employees feel that the passive collection of relational data is an invasion of privacy" (p. 16).

Moreover, Khan and Tang (2017) suggest that "Some seemingly well-intentioned and potentially useful endeavours to monitor key performance indicators, analyze areas in need of improvement', and optimize workforce scheduling and allocation can quickly spiral out of control, at least as viewed by the workforce, and could evoke visceral and negative responses from employees" (p. 58).

Together with organizations enhancing their methods to monitor and collect data within the organization, this has led to the collection of employee data beyond the working environment, thus encompassing an employee's personal and private lives blurring the lines and raising numerous ethical and privacy issues (Khan and Tang, 2017; Jeske and Calvard, 2020).

For instance, Jeske and Calvard (2020) suggest that organizations "are able to monitor employees during their offsite activities via their mobile devices, network traffic and wearable devices" (p. 249).

This is echoed by Khan and Tang (2017), who state that "The boundaries of employee monitoring and related analytics are being extended from employees' work lives to well into their social and even physiological spaces” (p. 63).

Altogether, the adoption of HR technology and its ability to collect and analyze mass amounts of workforce data in the form of personal views, sentiments and behaviours comes 
with several benefits. For instance, by using employee data, HR departments have claimed they can make better and more informed recruitment and selection decisions (Harris et al., 2011; Rasmussen and Ulrich, 2015; Tursunbayeva et al., 2021), they can more efficiently identify training and development opportunities (Peeters et al., 2020; Tursunbayeva et al., 2021) and can reduce workplace stress (Kane, 2015). However, using employee data also poses significant risks and downsides for HR professionals despite its perceived value. For example, employees may feel that their privacy is being threatened if they are unsure about the type of data being gathered, data collection methods and how their data are being used (Chatterjee et al., 2021). To alleviate these concerns and standardize how employee data are used, countries have begun to implement regulations, such as the General Data Protection Regulation (GDPR) in Europe, to help mitigate the misuse of employee personal information. Furthermore, organizations have also started appointing roles such as Chief Data Officers and data governance committees responsible for the overall governance and implementation of ethical standards concerning organizational-wide data (Nie et al., 2019; Janssen et al., 2020; Shet et al., 2021). These efforts are directly related to ensuring employees are comfortable with how their data are being tracked and used for making decisions. As such, we suggest that being mindful of employees' privacy concerns, acting transparently and having open communication between employees and management on the use of employee data should offer more pros than cons. However, the caveat is that HR professionals need to be included in these committees to review the boundaries of data collection employed by the organization and continuously question what data is too invasive to collect.

\section{Discussion and future research}

People analytics has evolved and has made significant steps forward in several areas over the past decade. To better comprehend the potential future of people analytics, this study synthesized and critically evaluated the substantial increase of peer-reviewed articles focused on people analytics published in ABS ranked journals between 2011 and 2021.

\section{The promise of people analytics}

The promise that people analytics will allow organizations to make more evidence-based decisions and, in return, positively impact organizational performance underscores the current state of this developing area of research. People analytics has been considered a "game-changer" for the future of HR (van der Togt and Rasmussen, 2017), with the potential to further transform HR into a strategic business partner. Furthermore, advocates and supporters of people analytics also claim that by utilizing people analytics, organizations are more able to efficiently identify underlying patterns and trends in their workforce data, offering organizations a competitive advantage (van der Togt and Rasmussen, 2017; McIver et al., 2018; Schiemann et al., 2018; Leonardi and Contractor, 2019). As such, organizations have made significant investments in people analytics by purchasing and implementing HR technologies.

In practice, organizations have begun to form people analytics teams to gain competitive advantage (Peeters et al., 2020). These teams are tasked with exploiting insights derived from employee data in areas such as recruitment and selection, employee engagement diversity and inclusion, and retention and turnover (Falletta and Combs, 2020; Peeters et al., 2020). Several published case studies and organizational success stories demonstrate this, detailing how organizations have leveraged people analytics to enable their HR departments to address HR challenges. These success stories offer organizations hope that if their HR departments can effectively use workforce data coupled with sophisticated predictive people analytics, then they too can transform their HR department into a more strategic data-driven organizational function and positively impact organizational performance.

\section{Ongoing debates in people analytics}




\section{JOEPP \\ 9,2}

\section{The reality of people analytics}

In contrast, despite the promises offered by people analytics, the current reality of people analytics is more skeptical than optimistic, with several challenges and debates generating more questions than answers. Although people analytics are being widely implemented to aid in making workforce decisions, it remains unclear what people analytics is. For instance, some scholars consider it an organizational practice (Marler and Boudreau, 2017; Minbaeva, 2018), whereas others consider it an HR process (Huselid, 2018; McIver et al., 2018). Similarly, an agreement has yet to be reached on the concept of people analytics as various terms, such as HR analytics, workforce analytics, human capital analytics and HR metrics, have been used synonymously to describe the concept (Huselid, 2018). Confusion between the terms and their associated definitions highlights a significant need for further clarity on what constitutes people analytics. Furthermore, this inconsistency raises concerns given that current definitions do not adequately address the depth of people analytics or actively elaborate on the various stages of people analytics maturity. Accordingly, the reality of people analytics is not a "one-size-fits-all" solution, as suggested in the extant literature. Instead, people analytics is situational and falls along a spectrum, where organizations at the low end of maturity report on descriptive statistics. In contrast, organizations at the highest and most mature level of people analytics can utilize descriptive statistics in addition to AI, $\mathrm{ML}$ and organizational network analysis tools to analyze historical and real-time workforce data to perform predictive and prescriptive analytics.

Equally important are the issues raised concerning whether the $\mathrm{HR}$ function is poised and ready to engage in people analytics. Although people analytics has come a long way, the current reality and a common theme faced by most organizations cited in the academic literature is a shortage of analytical understanding and high-quality data needed to conduct people analytics. Moreover, scholars have questioned the HR technology, claiming it may not be sophisticated enough to perform predictive and prescriptive people analytics. Considering that analytical understanding, technology and high-quality, reliable data are critical for people analytics success, missing any one of these elements significantly hinders the ability of people analytics to generate actionable insights. For example, if people analytics teams do not have the analytical understanding and capabilities to run analysis, having high-quality and reliable data offers HR departments no value since, without these competencies and skills, team members will not gain valuable insight from the data. Likewise, if teams cannot trust HR data given the likelihood of missing values and wrong entries, having the analytical understanding and capabilities will only aid in running inaccurate analysis, thus generating little to no value. These gaps call into question HR's readiness to adopt people analytics altogether, perpetuating the emerging argument and debate on whether people analytics may benefit from being removed from the HR function and ownership be transferred to a centralized analytics department.

Lastly, the influence of people analytics and organizations using technology, including AI, to collect, analyze and make decisions with sensitive workforce data, is a serious issue involving employee privacy and security (Jeske and Calvard, 2020; Chatterjee et al., 2021) and has moved beyond ethics and privacy raising questions of organizational control (Kellogg et al., 2020; Tursunbayeva et al., 2021). For instance, preserving employee privacy presents a significant HR challenge as organizations continue to collect workforce data from various mediums, such as text messages, email, social media, microphones, motion sensors and wearable technology, to facilitate efficient decision-making (Kane, 2015; Khan and Tang, 2017; Chatterjee et al., 2021). These forms of employee monitoring and surveillance infringe upon workers' privacy and impose new forms of organizational control by continuously monitoring them inside and outside their place of employment (Kane, 2015; Kellogg et al., 2020). Furthermore, more advanced forms of technology, such as wearables (i.e. smartwatches, chip implants, body-tracker devices, etc.), carry their own set of privacy 
issues as they can report on sensitive health metrics (i.e. weight, diet, exercise, stress level, and sleep patterns). These data can then be exploited by organizations to make workforce decisions, which have raised several concerns from the perspective of employees (Khakurel et al., 2018).

\section{The future of people analytics}

Despite its progress and increasing interest over the past several years, people analytics remains an underdeveloped and underexplored discipline within HRM research. Consequently, this presents academics and practitioners with a unique opportunity to make significant contributions and shape the direction and the future of people analytics research. Together with the growing interest and usage of people analytics in practice, academic research plays a fundamental role in furthering the field of people analytics. Such research offers insight into how HR can effectively respond to the challenges and opportunities presented by the digitalization of HRM. Accordingly, this study provides six research questions aimed at inspiring further research that will help narrow the gap between the promise and reality of people analytics as well as stimulate discussion and perhaps new debates within the field.

(1) What existing theories can offer insight into evaluating people analytics success?

People analytics research has primarily focused on issues surrounding people analytics in practice (Marler and Boudreau, 2017; Minbaeva, 2017, 2018). Although research highlighting the use cases of people analytics is necessary, this has led to a narrow research agenda concentrated on the application of people analytics rather than examining the phenomenon from a theoretical perspective. As such, it is imperative that empirical work demonstrating the theoretical relationship and antecedents between people analytics and overall organizational performance is conducted (Minbaeva, 2017, 2018; McIver et al., 2018). For example, despite the claims that people analytics will aid in solving HR and business challenges, there is little evidence to support that HR departments implementing people analytics see any return on investment or value. Similarly, scholars need to examine how people analytics can provide value not only at the organizational level but at the individual and team level and how this success is evaluated. This research area is critically important in the development of people analytics as there is currently little evidence linking people analytics to HR outcomes, making it unclear whether organizations should be investing in people analytics altogether. Moreover, even less evidence is available suggesting that HR departments employing advanced forms of technology such as AI, ML and organizational network analysis coupled with relational data see any additional value regarding organizational or unit-level performance (Gelbard et al., 2018; Gittell and Ali, 2021). Against this backdrop, we propose researchers focus on theorizing and linking people analytics to various multi-level outcomes through existing human capital and HRM theories to strengthen the argument for adopting people analytics. For example, scholars can draw on theories, such as the resource-based view or knowledge-based view, to argue how people analytics might impact organizational outcomes, such as financial success or innovation. Similarly, scholars taking a unit-level approach might turn to human capital or the human capital resource framework to justify the impact of people analytics on unit-level outcomes. In a similar vein, scholars may utilize relational data coupled with actor-network theory to gain insight into potential complementarity relationships that may lead to competitive advantage. Table 5 offers several examples of research areas and potential theoretical lenses that could be adopted to examine the impact and success of people analytics.

(2) How can researchers bridge the academic-practitioner gap?

A shared understanding of people analytics among researchers and practitioners is required. This shared understanding is critical, as collaboration between practitioners and researchers 


\section{JOEPP \\ 9,2}

\begin{tabular}{|c|c|c|}
\hline $\begin{array}{l}\text { Level of } \\
\text { analysis }\end{array}$ & Areas for further research & Theoretical lenses \\
\hline Individual & $\begin{array}{l}\text { - How can people analytics aid in addressing issues } \\
\text { concerning: } \\
\text { - Employee engagement } \\
\text { - Employee trust } \\
\text { - Employee well-being } \\
\text { - HR development } \\
\text { - Job satisfaction } \\
\text { - Recruitment and selection } \\
\text { Turnover/turnover intention }\end{array}$ & $\begin{array}{l}\text { Agency theory } \\
\text { AMO (Ability-motivation- } \\
\text { opportunity) } \\
\text { Equity theory } \\
\text { Human capital } \\
\text { Information boundary theory } \\
\text { Job demands resource model } \\
\text { Social exchange theory }\end{array}$ \\
\hline Team & $\begin{array}{l}\text { - What makes people analytics teams successful? } \\
\text { - What is the ideal team size and most important roles } \\
\text { found within people analytics teams? } \\
\text { Does team size and role differ between level of analytics } \\
\text { maturity and industry sector? } \\
\text { - How can people analytics teams contribute to HR } \\
\text { outcomes? How is people analytics success defined and } \\
\text { measured? } \\
\text { - Do organizations that use advanced technology and } \\
\text { people analytics benefit more than those organizations } \\
\text { who do not? }\end{array}$ & $\begin{array}{l}\text { Human capital } \\
\text { Human capital resources } \\
\text { framework } \\
\text { Theory of human capital } \\
\text { complementarities } \\
\text { Complex adaptive systems } \\
\text { theory } \\
\text { Actor-network theory } \\
\text { Institutional theory } \\
\text { Resource-based view } \\
\text { Knowledge-based view }\end{array}$ \\
\hline Organizational & $\begin{array}{l}\text { - Linking people analytics to organizational outcomes } \\
\text { including: } \\
\text { - Financial success } \\
\text { - Innovation } \\
\text { - Sustainability } \\
\text { Navigating times of change and crisis }\end{array}$ & $\begin{array}{l}\text { Dynamic capabilities } \\
\text { Resource orchestration }\end{array}$ \\
\hline
\end{tabular}

Table 5.

Examples of future research avenues for people analytics researchers

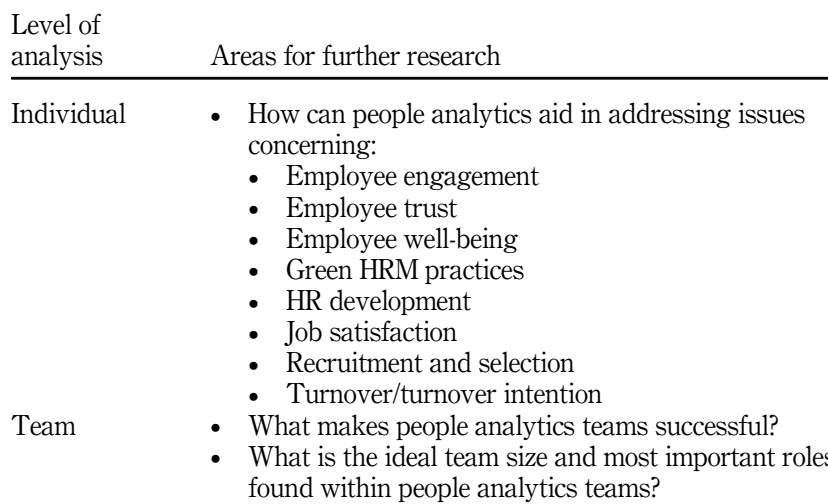


The digital transformation and shift of HRM influenced by the adoption and implementation of IT will significantly impact the demands and responsibilities of HR professionals moving forward (Cohen, 2015; Stone et al., 2015). Although much research has been conducted identifying the skills and competencies required by HR professionals to perform people analytics, what remains unclear is which skills are most influential to people analytics success and whether the skills gap in people analytics has seen any progress over the past several years. Likewise, research investigating how HR departments can effectively use people analytics to acquire and develop highly specialized skill sets is unexplored in the existing literature. Together, these gaps present a significant opportunity for researchers to further investigate what skills are needed for people analytics success and how people analytics can acquire specific competencies and skills that can lead to competitive advantage. Therefore, further research should conduct studies focused on empirically testing various individual skills and their impact on people analytics success. Additionally, research should also focus on how people analytics can help facilitate acquiring and developing talent. For example, how can people analytics influence succession planning activities, and how can people analytics be leveraged to identify members of the organization who may be suitable for filling hard-to-fill roles and internal vacancies? In other words, how can people analytics be used to create and develop human capital resources within an organization?

(4) What ethical and privacy concerns arise as a result of people analytics?

As organizations continue to utilize technology to collect and analyze higher volumes of sensitive employee data to make workforce decisions, this raises several concerns around employee privacy and ethical use of data, concepts that are currently underdeveloped within the existing people analytics literature. For example, collecting and exploiting sensitive workforce data (i.e. social network data and sensitive health metrics) raises several ethical concerns, including what types of employee data are too invasive to collect? And should sensitive employee data should be exploited for the benefit of increasing organizational performance. Moreover, drawing on the recent work of Kellogg et al. (2020), this facilitates questions involving algorithmic recording, such as how and when should organizations monitor employees with these new forms of technology? And how does the implementation of $\mathrm{AI}$ and ML techniques, in addition to algorithmic management, integrate with existing HRM decision-making without being too invasive? Or, in terms of algorithmic replacing, should these algorithms have the autonomy to use people data to make termination decisions? These areas for future research would significantly progress people analytics research while integrating other subfields in HRM.

Similarly, the "dark side" and potential negative impact of using AI and people analytics on employee job outcomes, such as job satisfaction, organizational justice, employee wellbeing and trust, have not been significantly addressed within the extant people analytics literature. For example, from the perspective of organizational injustice, if HR departments begin to make decisions through the output of an algorithm rather than human experience and intuition, this proposes the question of at what point could people analytics do more harm than good? Furthermore, as HR departments continue to adopt AI and ML technology to perform and automate various HR deliverables, it will become critically important to understand the impact and the fallout that this may have on employees and HR data governance policies. For instance, will employees trust AI algorithms to make organizational decisions that affect their livelihood? Thus, we recommend future research to explore the ethical, privacy and security implications of using sensitive workforce data. Such research should strive to simultaneously address employee perceptions and the potential negative impact of people analytics on employee job outcomes, such as job satisfaction, employee engagement, organizational trust, etc. Additionally, although countries are implementing regulations to oversee the use of employee data (i.e. GDPR), more research examining how

\section{Ongoing debates in people analytics}


JOEPP
9,2

300

data governance policies are adapting and evolving to account for AI and ML adoption is also of utmost importance.

(5) Does ownership of people analytics matter?

Recently, some scholars have begun to question whether HR should retain ownership of people analytics or whether it is more appropriate for the function to be relocated outside of HR. To offer insight into this debate, perhaps instead of discussing who should take ownership of people analytics, the question posed should be what impact people analytics has on the organization depending on their organizational reporting structure. In other words, does having a people analytics team within HR or outside of HR have a more significant business impact? Moreover, it would be interesting to examine whether the location of people analytics is dependent on people analytics maturity. For example, do organizations at the higher end of people analytics maturity situate their people analytics function outside of HR or visa-versa? And if they have relocated, at what level of maturity should they be reassigned? Furthermore, research is needed to better understand if keeping the people analytics function within HR may have spillover effects. For instance, does keeping people analytics within HR aid in the overall credibility and visibility of the function?

(6) How can people analytics empower employees and organizations in times of crisis?

The Covid-19 pandemic has caused significant disruption over the past two years, forcing organizations globally to adapt to the unprecedented shift in workplace demands. In light of Covid-19, organizations have taken several precautions to preserve their employees' psychical health and well-being. For example, more employees are working from home to reduce their risk of exposure and spreading the virus. However, as a result of these safety measures, employees could develop adverse outcomes regarding mental well-being, engagement and productivity. For instance, employees may feel less connected to their coworkers and team members due to the inability to interact face-to-face. The pandemic and the "new normal" moving beyond Covid-19 have given rise to people analytics' opportunity to play a vital role in aiding leadership in times of crisis and transition to make informed and strategic workforce decisions quickly. Accordingly, we propose future research to examine how people analytics can help leadership navigate and influence decision-making in times of crisis and, more broadly, explore how people analytics can be used to empower employees and organizations in times of turbulence and change.

\section{Conclusion}

Although considerable progress has been made in the emerging area of people analytics, it is evident that the field has much to overcome concerning the challenges raised within this review. As such, this systematic review set out to offer a greater level of understanding of people analytics by synthesizing and critically evaluating the people analytics literature produced between 2011 and 2021. Drawing on 46 peer-reviewed articles representing 26 ABS ranked journals, this review offers insight into what debates and issues are emerging as a result of people analytics adoption. As a result, this review presents a comprehensive research agenda demonstrating the need for collaboration between scholars and practitioners to successfully align the promise and the current reality of people analytics.

\section{References}

Andersen, M.K. (2017), "Human capital analytics: the winding road", Journal of Organizational Effectiveness, pp. 133-136, doi: 10.1108/JOEPP-03-2017-0024.

Angrave, D., Charlwood, A., Kirkpatrick, I., Lawrence, M. and Stuart, M. (2016), "HR and analytics: why HR is set to fail the big data challenge", Human Resource Management Journal, Vol. 26 No. 1, pp. 1-11, doi: 10.1111/1748-8583.12090. 
Aral, S., Brynjolfsson, E. and Wu, L. (2012), "Three-way complementarities: performance pay, human resource analytics, and information technology", Management Science, Vol. 58 No. 5, pp. 913-931, doi: 10.1287/mnsc.1110.1460.

Baesens, B., De Winne, S. and Sels, L. (2017), "Is your company ready for HR analytics?", MIT Sloan Management Review, Vol. 58 No. 2, pp. 20-21, doi: 10.1016/j.jsmc.2005.11.006.

\section{Ongoing debates in people analytics}

Ben-Gal, H.C. (2019), “An ROI-based review of HR analytics: practical implementation tools”, Personnel Review, Vol. 48 No. 6, pp. 1429-1448, doi: 10.1108/PR-11-2017-0362.

Bleijenbergh, I., van Mierlo, J. and Bondarouk, T. (2020), "Closing the gap between scholarly knowledge and practice: guidelines for HRM action research", Human Resource Management Review, Elsevier, Vol. 31 No. 2, pp. 1-13, doi: 10.1016/j.hrmr.2020.100764.

Boudreau, J. and Cascio, W. (2017), "Human capital analytics: why are we not there?", Journal of Organizational Effectiveness: People and Performance, Vol. 4 No. 2, pp. 119-126, doi: 10.1108/ JOEPP-03-2016-0029.

Boyatzis, R.E. (1998), Transforming Qualitative Information: Thematic Analysis and Code Development, Sage, Thousand Oaks, CA.

Braun, V. and Clarke, V. (2006), "Using thematic analysis in psychology", Qualitative Research in Psychology, Vol. 3, pp. 77-101, doi: 10.1017/CBO9781107415324.004.

Buttner, H. and Tullar, W. (2018), "A representative organizational diversity metric: a dashboard measure for executive action", Equality, Diversity and Inclusion: An International Journal, Vol. 37 No. 3, pp. 219-232, doi: 10.1108/GM-12-2013-0140.

Chatterjee, S., Chaudhuri, R., Vrontis, D. and Siachou, E. (2021), "Examining the dark side of human resource analytics: an empirical investigation using the privacy calculus approach", International Journal of Manpower, doi: 10.1108/IJM-02-2021-0087.

Cohen, D.J. (2015), "HR past, present and future: a call for consistent practices and a focus on competencies", Human Resource Management Review, Elsevier, Vol. 25 No. 2, pp. 205-215, doi: 10.1016/j.hrmr.2015.01.006.

Deloitte (2017), Rewriting the Rules for the Digital Age: 2017 Deloitte Global Human Capital Trends, Deloitte, New York, NY.

Edwards, M.R. and Edwards, K. (2019), Predictive HR Analytics: Mastering the HR Metric, 2nd ed., Kogan Page, London.

Falletta, S.V. and Combs, W.L. (2020), "The HR analytics cycle: a seven-step process for building evidence-based and ethical HR analytics capabilities", Journal of Work-Applied Management. doi: 10.1108/JWAM-03-2020-0020.

Fereday, J. and Muir-Cochrane, E. (2017), "Demonstrating rigor using thematic analysis: a hybrid approach of inductive and deductive coding and theme development", International Journal of Qualitative Methods, Vol. 5 No. 1, pp. 80-92, doi: 10.1177/160940690600500107.

Fernandez, V. and Gallardo-Gallardo, E. (2020), "Tackling the HR digitalization challenge: key factors and barriers to HR analytics adoption", Competitiveness Review: An International Business Journal. doi: 10.1108/CR-12-2019-0163.

Gartner (2021), Gartner Magic Quadrent for Cloud HCM Suits.

Gelbard, R., Gonen, R.R., Carmeli, A. and Talyansky, R. (2018), "Sentiment analysis in organizational work: towards an ontology of people analytics”, Expert Systems, Vol. 35, pp. 1-15, doi: 10.1111/ exsy.12289.

Gittell, J. and Ali, H. (2021), "Relational analytics: guidelines for analysis and action", Angewandte Chemie International Edition, Routledge, Vol. 6 No. 11, pp. 951-952.

Glaser, B. and Strauss, A. (1967), The Discovery of Grounded Theory, Aldine Publishing Company, Hawthorne, NY. 

JOEPP
9,2

Greasley, K. and Thomas, P. (2020), "HR analytics: the onto-epistemology and politics of metricised HRM”, Human Resource Management Journal, Vol. 30 No. 4, pp. 1-14, doi: 10.1111/1748-8583.12283.

Green, D. (2017), "The best practices to excel at people analytics",Journal of Organizational Effectiveness: People and Performance, Vol. 4 No. 2, pp. 137-144, doi: 10.1108/JOEPP-03-2017-0027.

Harris, J.G., Craig, E. and Light, D.A. (2011), "Talent and analytics: new approaches, higher ROI", Journal of Business Strategy, Vol. 32 No. 6, pp. 4-13, doi: 10.1108/02756661111180087.

Hurrell, S.A., Scholarios, D. and Richards, J. (2017), “The kids are alert': generation Y responses to employer use and monitoring of social networking sites", New Technology, Work and Employment, Vol. 32 No. 1, pp. 64-83, doi: 10.1111/ntwe.12085.

Huselid, M.A. (2018), "The science and practice of workforce analytics: introduction to the HRM special issue”, Human Resource Management, Vol. 57 No. 3, pp. 679-684, doi: 10.1002/hrm.21916.

Ibrahim, M. (2012), "Thematic analysis: a critical review of its its processes and evaluation”, West East Journal of Social Sciences, Vol. 1 No. 1, pp. 39-47, available at: http://www.westeastinstitute.com/ journals/wp-content/uploads/2013/02/4-Mohammed-Ibrahim-Alhojailan-Full-Paper-ThematicAnalysis-A-Critical-Review-Of-Its-Process-And-Evaluation.pdf.

Janssen, M., Brous, P., Estevez,E., Barbosa, L.S. and Janowski, T.(2020), "Data governance: organizing data for trustworthy artificial intelligence", Government Information Quarterly, Elsevier, Vol. 37 No. 3, p. 101493, doi: 10.1016/j.giq.2020.101493.

Jeske, D. and Calvard, T. (2020), "Big data: lessons for employers and employees”, Employee Relations, Vol. 42 No. 1, pp. 248-261, doi: 10.1108/ER-06-2018-0159.

Kane, G. (2015), “People analytics through super-charged ID”, MIT Sloan Management Review, available at: https://sloanreview.mit.edu/article/people-analytics-through-super-charged-id-badges/.

Kapoor, B. and Sherif, J. (2012), "Human resources in an enriched environment of business intelligence", Kybernetes, Vol. 44 No. 10, pp. 1625-1637, doi: 10.1108/K-01-2015-0009.

Kellogg, K.C., Valentine, M.A. and Christin, A. (2020), "Algorithms at work: the new contested terrain of control”, Academy of Management Annals, Vol. 14 No. 1, pp. 366-410, doi: 10.5465/annals. 2018.0174 .

Khakurel, J., Melkas, H. and Porras, J. (2018), "Tapping into the wearable device revolution in the work environment: a systematic review", Information Technology and People, Vol. 31 No. 3, pp. 791-818, doi: 10.1108/ITP-03-2017-0076.

Khan, S. and Tang, J. (2017), "The paradox of human resource analytics: being mindful of employees", Journal of General Management, Vol. 42 No. 2, pp. 57-66.

King, K.G. (2016), "Data analytics in human resources: a case study and critical review", Human Resource Development Review, Vol. 15 No. 4, pp. 487-495, doi: 10.1177/1534484316675818.

Kryscynski, D., Reeves, C., Stice-Lusvardi, R., Ulrich, M. and Russell, G. (2018), "Analytical abilities and the performance of HR professionals", Human Resource Management, Vol. 57 No. 3, pp. 715-738, doi: 10.1002/hrm.21854.

Larsson, A.S. and Edwards, M.R. (2021), "Insider econometrics meets people analytics and strategic human resource management", International Journal of Human Resource Management, Routledge, pp. 1-47, doi: 10.1080/09585192.2020.1847166.

Leonardi, P. and Contractor, N. (2019), "Better people analytics", Harvard Business Review, Vol. 96 No. 6, pp. 70-81.

Levenson, A. (2018), "Using workforce analytics to improve strategy execution", Human Resource Management, Vol. 57 No. 3, pp. 685-700, doi: 10.1002/hrm.21850.

Levenson, A. and Fink, A. (2017), "Human capital analytics: too much data and analysis, not enough models and business insights", Journal of Organizational Effectiveness, Vol. 4 No. 2, pp. 145-156, doi: 10.1108/JOEPP-03-2017-0029.

Lewin, K. (1946), “Action research and minority problems”, Journal of Social Issues, Vol. 2 No. 4, pp. 34-46, doi: 10.1037/10269-013. 
Liamputtg, P. (2009), "Qualitative data analysis: conceptual and practical considerations", Health Promotion Journal of Australia, Vol. 20 No. 2, pp. 133-139, doi: 10.1071/he09133.

Margherita, A. (2020), Human resources analytics: a systematization of research topics and directions for future research, Human Resource Management Review, Elsevier, p. 100795, doi: 10.1016/j. hrmr.2020.100795.

Marler, J.H. and Boudreau, J.W. (2017), "An evidence-based review of HR analytics", International Journal of Human Resource Management, Routledge, Vol. 28 No. 1, pp. 3-26, doi: 10.1080/ 09585192.2016.1244699.

McCartney, S., Murphy, C. and McCarthy, J. (2020), "21st century HR: a competency model for the emerging role of HR Analysts”, Personnel Review, Vol. 50 No. 6, pp. 1495-1513.

McIver, D., Lengnick-Hall, M.L. and Lengnick-Hall, C.A. (2018), "A strategic approach to workforce analytics: integrating science and agility", Business Horizons, Kelley School of Business, Indiana University, Vol. 61 No. 3, pp. 397-407, doi: 10.1016/j.bushor.2018.01.005.

Minbaeva, D. (2017), "Human capital analytics: why aren't we there? Introduction to the special issue", Journal of Organizational Effectiveness, Vol. 4 No. 2, pp. 110-118, doi: 10.1108/JOEPP-042017-0035.

Minbaeva, D. (2018), "Building credible human capital analytics for organizational competitive advantage", Human Resource Management, Vol. 57 No. 3, pp. 701-713, doi: 10.1002/hrm.21848.

Nie, Y., Talburt, J., Dagtas, S. and Feng, T. (2019), "The influence of chief data officer presence on firm performance: does firm size matter?", Industrial Management and Data Systems, Vol. 119 No. 3, pp. 495-520, doi: 10.1108/IMDS-03-2018-0101.

Nielsen, C. and McCullough, N. (2018), "How people analytics can help you change process, culture, and strategy", Harvard Business Review, May, pp. 2-6.

Pape, T. (2016), "Prioritising data items for business analytics: framework and application to human resources", European Journal of Operational Research, Vol. 252 No. 2, pp. 687-698, doi: 10.1016/j. ejor.2016.01.052.

Peeters, T., Paauwe, J. and Van De Voorde, K. (2020), "People analytics effectiveness: developing a framework", Journal of Organizational Effectiveness, Vol. 7 No. 2, pp. 203-219, doi: 10.1108/ JOEPP-04-2020-0071.

Pessach, D., Singer, G., Avrahami, D., Ben-Gal, H., Shmueli, E. and Ben-Gal, I. (2020), "Employees recruitment: a prescriptive analytics approach via machine learning and mathematical programming", Decision Support Systems, Vol. 134, doi: 10.1016/j.dss.2020.113290.

Rasmussen, T. and Ulrich, D. (2015), "Learning from practice: how HR analytics avoids being a management fad", Organizational Dynamics, Elsevier, Vol. 44 No. 3, pp. 236-242, doi: 10.1016/j. orgdyn.2015.05.008.

Safarishahrbijari, A. (2018), "Workforce forecasting models: a systematic review", Journal of Forecasting, Vol. 37, pp. 739-753, doi: 10.1002/for.2541.

Schiemann, W.A., Seibert, J.H. and Blankenship, M.H. (2018), "Putting human capital analytics to work: predicting and driving business success", Human Resource Management, Vol. 57 No. 3, pp. 795-807, doi: 10.1002/hrm.21843.

Sharma, A. and Sharma, T. (2017), "HR analytics and performance appraisal system: a conceptual framework for employee performance improvement", Management Research Review, Vol. 40 No. 6, pp. 684-697, doi: 10.1108/MRR-04-2016-0084.

Shet, S.V., Poddar, T., Wamba, S.F. and Dwivedi, Y.K. (2021), "Examining the determinants of successful adoption of data analytics in human resource management - a framework for implications", Journal of Business Research, Vol. 131, pp. 311-326, doi: 10.1016/j.jbusres.2021.03.054.

Short, D. (2006), "Closing the gap between research and practice in HRD”, Human Resource Development Quarterly, Vol. 17 No. 3, pp. 343-350, doi: 10.1002/hrdq.

Simmons, N. (2018), "Axial coding”, The SAGE Encyclopedia of Communication Research Methods, Sage, Thousand Oaks, CA. 

JOEPP
9,2

\section{4}

Simón, C. and Ferreiro, E. (2018), "Workforce analytics: a case study of scholar-practitioner collaboration”, Human Resource Management, Vol. 57 No. 3, pp. 781-793, doi: 10.1002/hrm.21853.

Sivathanu, B. and Pillai, R. (2020), "Technology and talent analytics for talent management - a game changer for organizational performance", International Journal of Organizational Analysis, Vol. 28 No. 2, pp. 457-473, doi: 10.1108/IJOA-01-2019-1634.

Stone, D.L. and Deadrick, D.L. (2015), "Challenges and opportunities affecting the future of human resource management”, Human Resource Management Review, Elsevier, Vol. 25 No. 2, pp. 139-145, doi: 10.1016/j.hrmr.2015.01.003.

Stone, D., Deadrick, D.L., Lukaszewski, K.M. and Johnson, R. (2015), "The influence of technology on the future of human resource management", Human Resource Management Review, Elsevier, Vol. 25 No. 2, pp. 216-231, doi: 10.1016/j.hrmr.2015.01.002.

Strohmeier, S. (2018), "Smart HRM a Delphi study on the application and consequences of the internet of things in human resource management", The International Journal of Human Resource Management, Vol. 31 No. 18, pp. 2289-2318.

Tursunbayeva, A., Di Lauro, S. and Pagliari, C. (2018), "People analytics-a scoping review of conceptual boundaries and value propositions", International Journal of Information Management, Elsevier, Vol. 43, pp. 224-247, doi: 10.1016/j.ijinfomgt.2018.08.002.

Tursunbayeva, A., Pagliari, C., Di Lauro, S. and Antonelli, G. (2021), "The ethics of people analytics: risks, opportunities and recommendations", Personnel Review, doi: 10.1108/PR-12-2019-0680.

Ulrich, D. and Dulebohn, J.H. (2015), “Are we there yet? What's next for HR?", Human Resource Management Review, Elsevier, Vol. 25 No. 2, pp. 188-204, doi: 10.1016/j.hrmr.2015.01.004.

Van de Ven, A.H. (2007), Engaged Scholarship, Oxford University Press, Oxford.

van den Heuvel, S. and Bondarouk, T. (2017), "The rise (and fall?) of HR analytics", Journal of Organizational Effectiveness: People and Performance, Vol. 4 No. 2, pp. 157-178, doi: 10. 1002/chir.

van der Togt, J. and Rasmussen, T.H. (2017), “Toward evidence-based HR”, Journal of Organizational Effectiveness, Vol. 4 No. 2, pp. 127-132, doi: 10.1108/JOEPP-02-2017-0013.

Vargas, R., Yurova, Y., Ruppel, Cynthia, Tworoger, L.C. and Greenwood, R. (2018), "Individual adoption of HR analytics: a fine grained view of the early stages leading to adoption", The International Journal of Human Resource Management, Routledge, Vol. 5192, pp. 1-22, doi: 10. 1080/09585192.2018.1446181.

Williams, M. and Moser, T. (2019), "The art of coding and thematic exploration in qualitative research", International Management Review, Vol. 15 No. 1, pp. 45-55.

\section{Corresponding author}

Steven McCartney can be contacted at: steven.mccartney@mu.ie 


\section{Appendix}

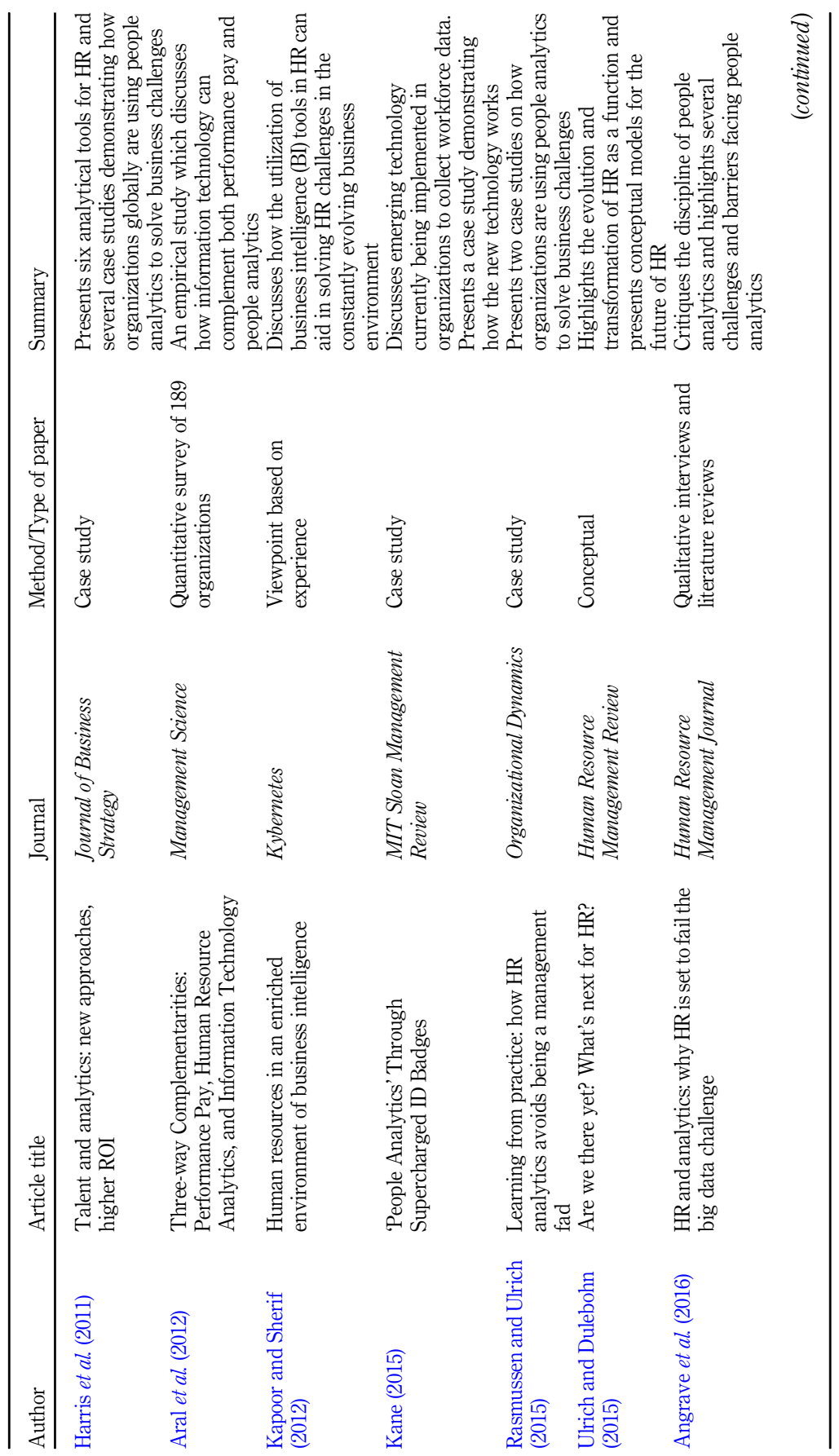

Ongoing debates in people analytics

305

Table A1.

Summary of ABS ranked journal articles included in the present review 


\section{JOEPP \\ 9,2}

306

Table A1.

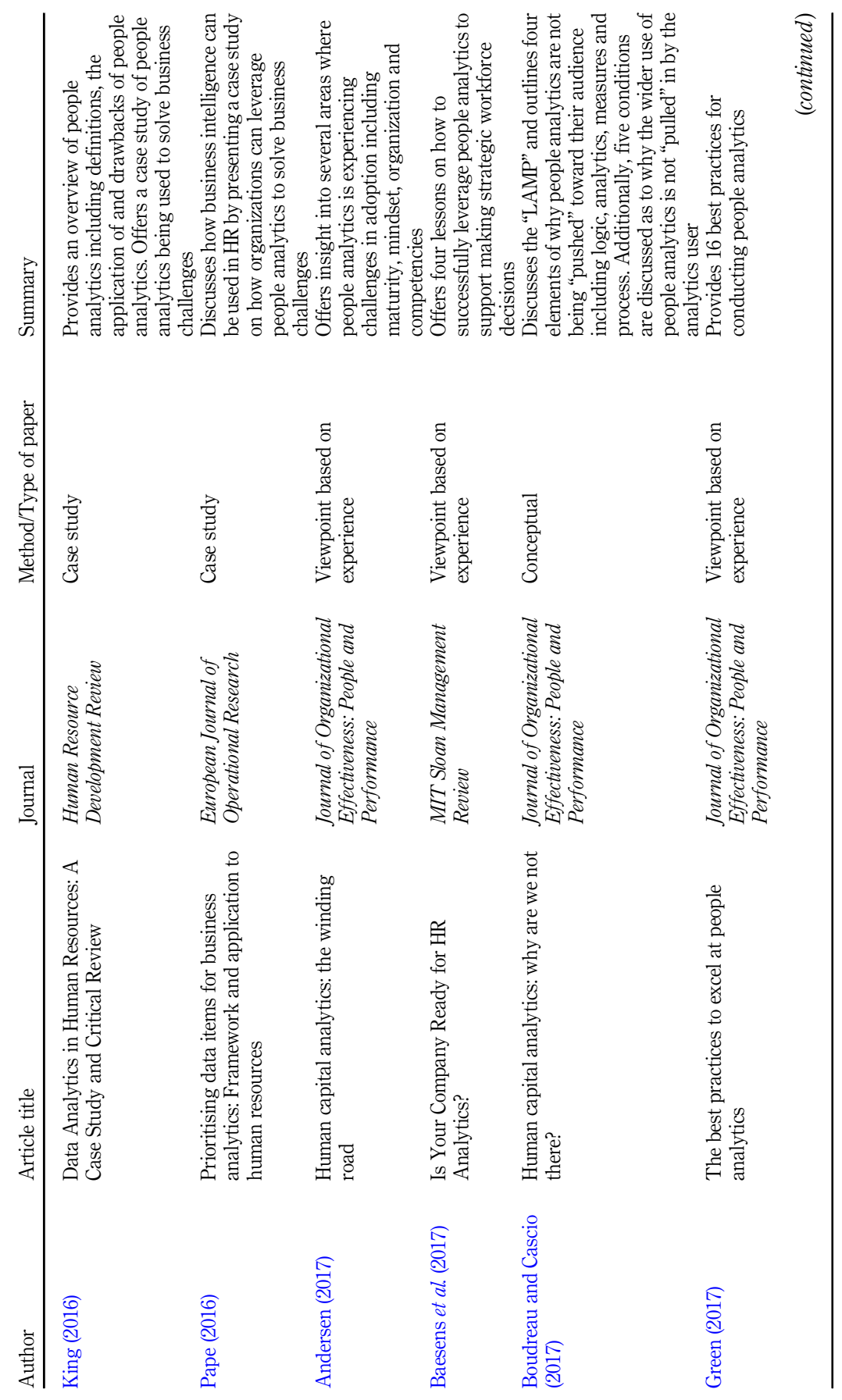




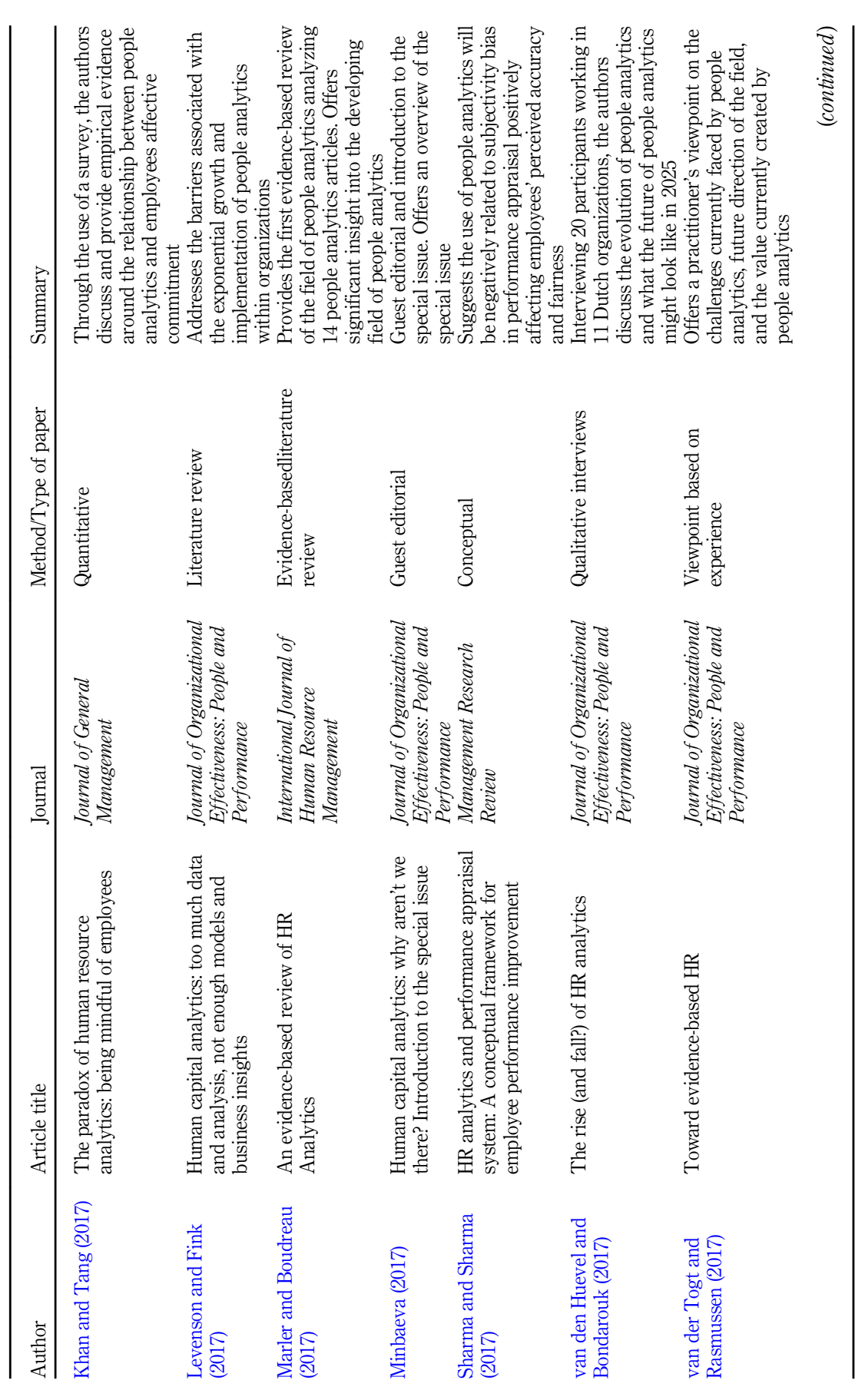

Ongoing

debates in people analytics

307

Table A1. 


\section{JOEPP \\ 9,2}

308

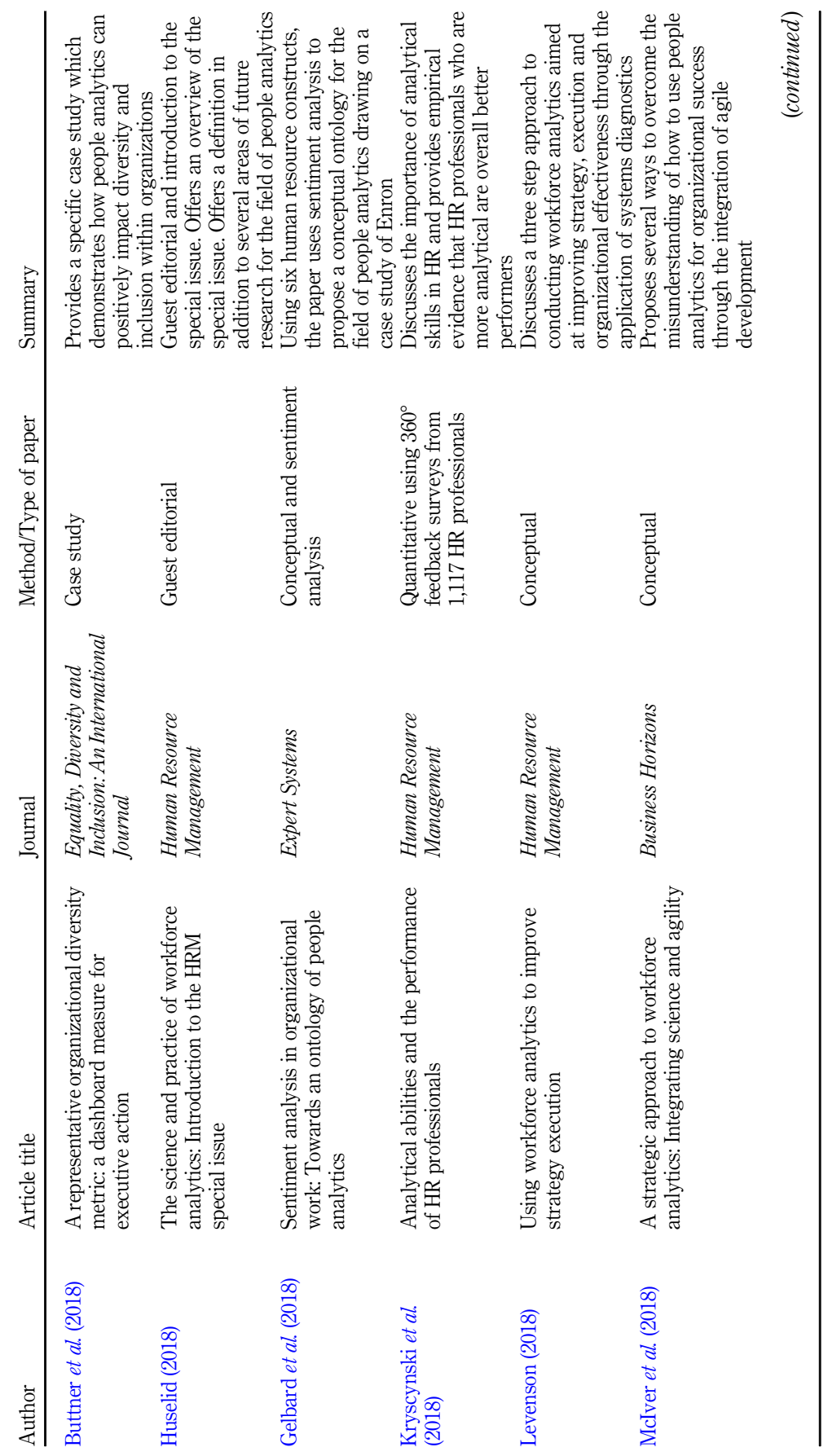




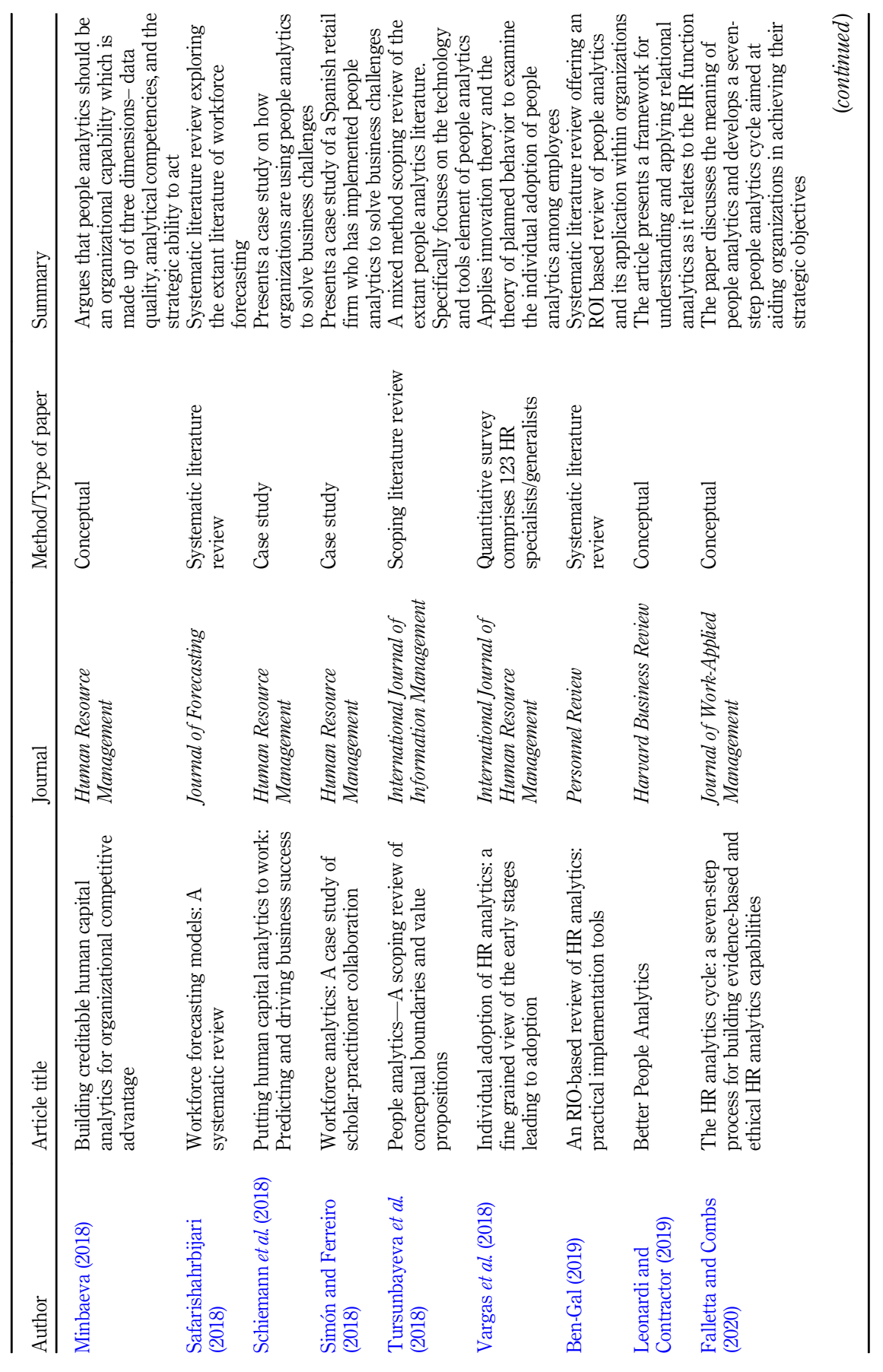

Ongoing

debates in people analytics

309

Table A1. 


\section{JOEPP \\ 9,2}

310

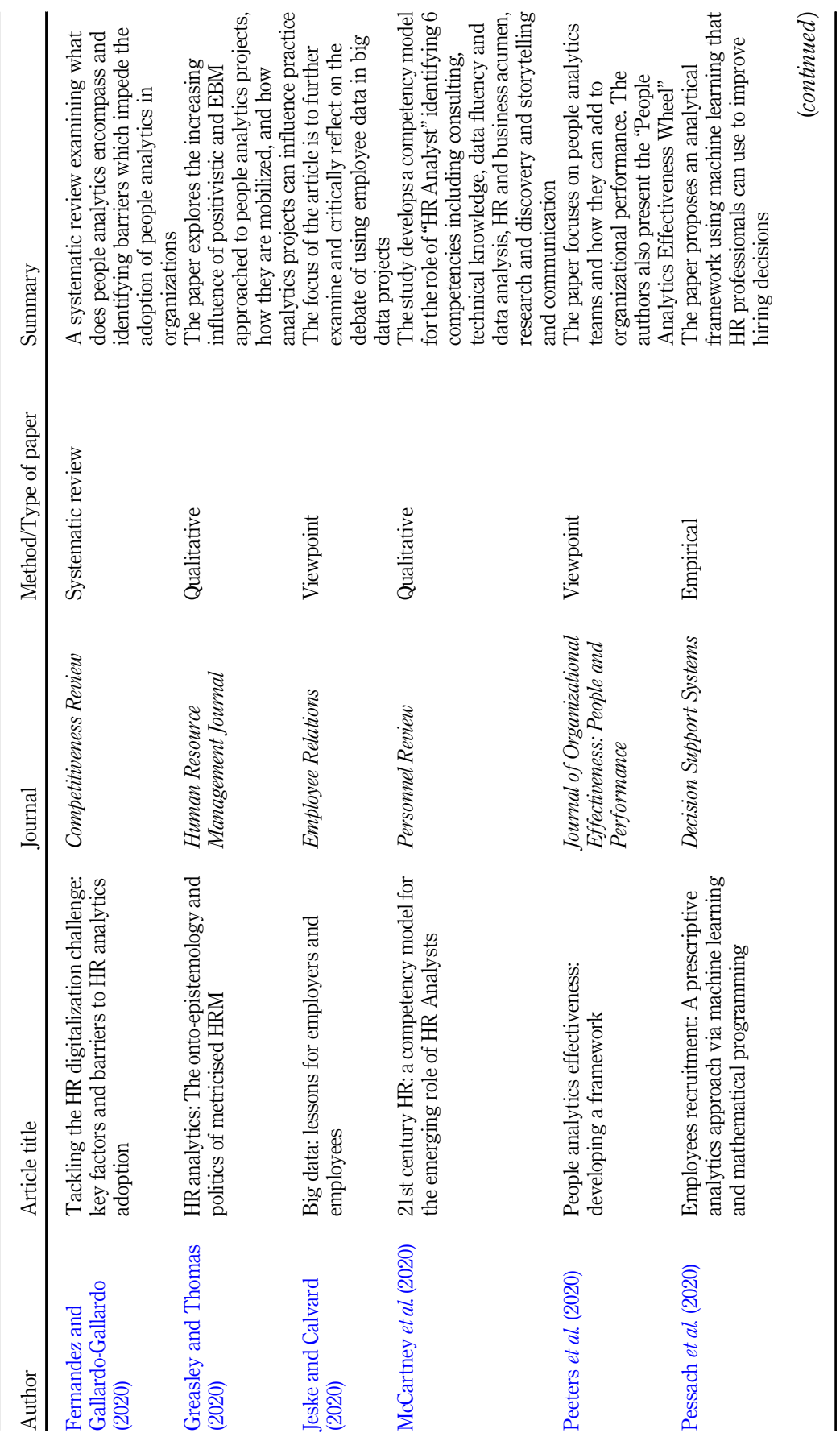

Table A1. 


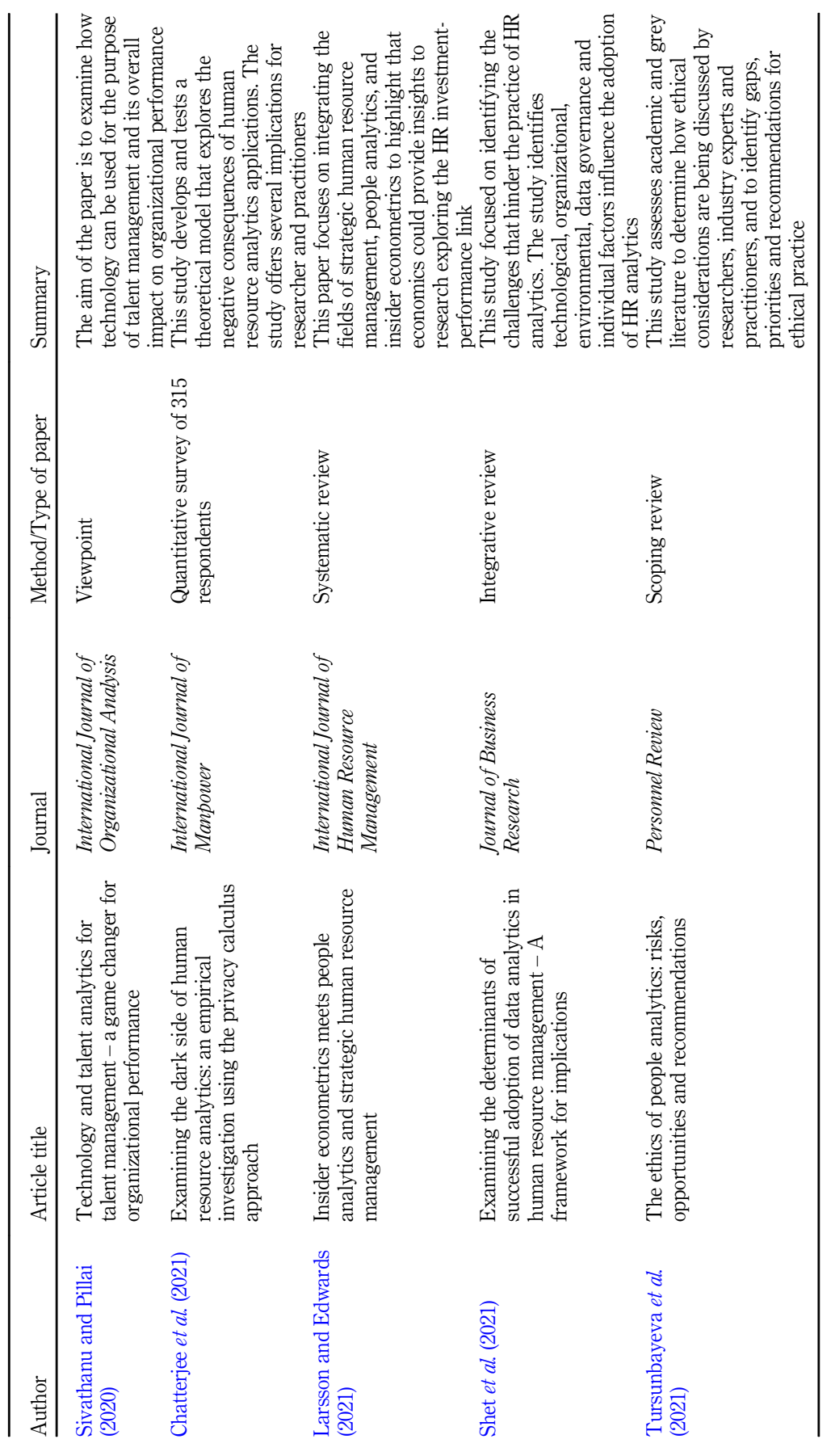

Ongoing
debates in
people
analytics

311

Table A1. 